\title{
Mechanical characteristics of compressed earth blocks, compressed stabilized earth blocks and stabilized adobe bricks with cement in the town of Ngaoundere - Cameroon
}

\author{
Goutsaya ${ }^{1^{*}}$, Ntamack GE ${ }^{1 *}$, Kenmeugne ${ }^{2}{ }^{2}$, Charif d'Ouazzane $\mathrm{S}^{3}$
}

1 Groupe de Mécanique, Matériaux et Acoustique (GMMA), Département de Physique, Faculté des Sciences, Université de Ngaoundéré, B.P.: 454 Ngaoundéré, Cameroun.

2 Département des Génies Industriel et Mécanique, Ecole Nationale Supérieure Polytechnique de Yaoundé, Université de Yaoundé 1, B.P.: 8390 Yaoundé, Cameroun

3 LMTM: Laboratoire de Mécanique, Thermique et Matériaux, Ecole Nationale Supérieure des Mines, Rabat, ENSM, B.P. 753 Rabat, Maroc.

* Corresponding Author: janviergoutsaya@gmail.com ; guyedgar@yahoo.fr

Received: 16-07-2021

Accepted: 25-11-2021

\begin{abstract}
The aim of this study is to examine the effects of cement stabilization on the mechanical stress of compressed stabilized earth blocks (CSEBs) and adobe stabilized earth bricks (ASEBs). Hence, this work is based on an experimental study carried out in order to determine the geotechnical properties of the samples soil, namely, the dry particle size analysis after washing, the particle size distribution by sedimentometry, Atterberg limits, and the preparation of specimens with different levels of cement proportions. Moreover, single compression and three-point bending compression out on specimens measuring $4 \times 4 \times 4 \mathrm{~cm}^{3}$ and $4 \times 4 \times 16 \mathrm{~cm}^{3}$ respectively. The findings indicate that dosing with $8 \%$ cement results in a clear increase in compression stress of approximately $25.55 \%$ for CSEBs compared to the reference set at $0 \%$ and $22.85 \%$ for ASEBs. On the other hand, for a dosage of $4 \%$, we observe a slight increase in stress by simple compression of around $3.26 \%$ for CSEBs and $3.14 \%$ for ASEBs. For three-point bending compression for a cement dosage of $8 \%$, there is also an increase in stress of about $25 \%$ for the CSEBs compared to the reference taken at $0 \%$ and $23.02 \%$ for the ASEBs.
\end{abstract}

Key words: Adobe earth bricks; adobe stabilized earth bricks, plasticity; stabilization; compressed earth blocks; compressed stabilized earth blocks.

\section{Introduction}

The earth has been one of the main construction materials used on our planet for almost 10.000 years. Today, more than one third of our planet's inhabitants live in earth-based habitats. The population of the town of Ngaoundere mostly build in adobe earth bricks, owing to the quality and availability of its red clay soil. Studies on compressed stabilized earth blocks (CEBs) have been carried out by several researchers (Walker, 2004; Kariyawasam and Jayasinghe, 2016; Zhang et al., 2017; Toure et al., 2017; Sekhar and Nayak, 2018; Ruiz, 2018; Inim et al., 2018). The research shows that, the bonding materials have an effect on the overall stability of masonry structure (Ronglin, 2020). The axial compression failure initial cracks appeared on the contact surfaces of the two blocks, followed by cracking at the corner of the specimen (Guanqi et al., 2021). This material shows its current form with numerous assets necessary for the construction of sustainable, comfortable and economic accommodations (Houben et al., 1996; Césaire et al., 2020). The use of local materials to build houses is an important strategy to counter our worsening global environmental problems (Ghorab et al., 2007). However, the use of raw earth as a building material for adobe earth bricks presents significant limitations, such as the high absorption rate due to the relatively high porosity, the formation of drawback during drying and a low resistance to humidity. At the same time, it offers good thermal insulation properties when stabilized at ideal conditions (Meukam et al., 2004; Elisabete et al., 2020). In 
our study, we will determine the geotechnical properties of soil samples obtained from three experimental sites. These properties will be determined by dry particle size distribution after washing (grain sizes above $80 \mu \mathrm{m}$ ), particle size analysis by sedimentometry (grain sizes below $80 \mu \mathrm{m})$, Atterberg limits and the preparation of specimens with different cement dosages $(0 \%$, $04 \%, 08 \%$ ). Subsequently, the mechanical properties will be assessed on compressed earth blocks, compressed stabilized earth blocks (CSEBs), adobe earth bricks (AEBs) and adobe stabilized earth bricks (ASEBs) through simple compression tests, three-point bending compression and absorption tests.

\section{Material and methods}

\subsection{Location of the study and sampling areas}

The soil samples were collected in the Adamawa region (Ngaoundere town), located in the northern part of Cameroon, in the VINA division, more precisely in Ngaoundere I (Bamyanga: BAM), Ngaoundere II (Gadamabanga: GAD) and Ngaoundere III (Maiborno: MAI) sub-divisions. Soil samples were collected at $50 \mathrm{~cm}$ depth in these three neighbourhoods. This choice is based on the high number of constructions with adobe earth bricks, representing about $80 \%$ according to field surveys.

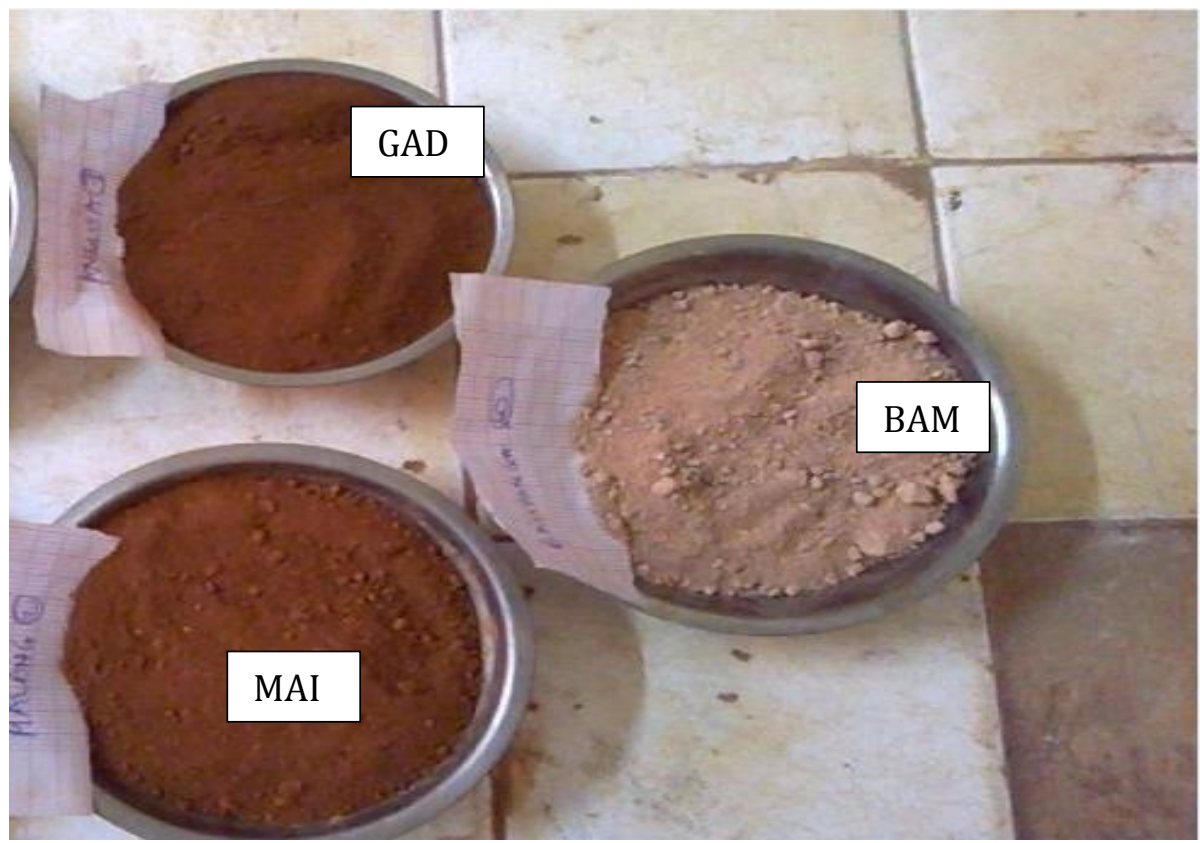

Fig. 1. Soil samples GAD, MAI and BAM

\subsection{Climate}

The Adamawa region has a tropical savana climate, and very wet given its high altitude, average $1100 \mathrm{~m}$. The Ngaoundere weather station receives up to $1575 \mathrm{~mm}$ of rain in seven months, from march to november (Amougou et al., 2015). The climate in this region is irregular, with a dry season lasting about 5 months, november to march, and a rainy season covering about 7 months, april to october. Average rainfall is between $900 \mathrm{~mm}$ and $1500 \mathrm{~mm}$. Minimum temperatures of $10-19^{\circ} \mathrm{C}$ are recorded from december to January and maximum temperatures are $27-34^{\circ} \mathrm{C}$ in 
march. Average temperatures are relatively low: $22^{\circ} \mathrm{C}$ in Ngaoundere, with an equally low annual temperature range of $3.1^{\circ} \mathrm{C}$ (Amougou et al., 2015).

\subsection{Geotechnical identification tests}

The geotechnical properties of the soil will help to understand and predict the behaviour of the material. The tests below were carried out on three soil samples collected at the Local Materials Promotion Authority (MIPROMALO) laboratory in Yaounde. These included: dry particle size analysis after washing: grains greater than $80 \mu \mathrm{m}$; particle size distribution by sedimentometry analysis: grains lower than $80 \mu \mathrm{m}$; Atterberg limits (Liquidity Limits: LL, Plastic Limits: PL and Plasticity Index: PI) and methylene blue test.

\subsection{Specimens fabrication}

\subsubsection{Test specimens fabrication of CEBs, CSEBs, AEBs and ASEBs}

The CEBs, CSEBs, AEBs and ASEBs specimens were made with the dimensions $4 \times 4 \times 16 \mathrm{~cm}^{3}$ for three-point bending tests, $4 \times 4 \times 4 \mathrm{~cm}^{3}$ for simple compression tests, $8 \times 4 \times 2 \mathrm{~cm}^{3}$ and $4 \times 4 \times 16 \mathrm{~cm}^{3}$ for absorption tests with different percentages of cement stabilization CPJ 35. The cement CPJ 35 is mainly composed of: $\mathrm{SiO}_{2} ; \mathrm{Al}_{2} \mathrm{O}_{3} ; \mathrm{Fe}_{2} \mathrm{O}_{3} ; \mathrm{CaO} ; \mathrm{MgO} ; \mathrm{SO}_{3} ; \mathrm{K}_{2} \mathrm{O} ; \mathrm{Na}_{2} \mathrm{O}$; free lime, insoluble residue with a compressive strength of 28MPa after 28 days (NF EN P15-101-1, 1995b).

\section{Procedures for the manufacturing of CEBs and CSEBs}

The manufacturing of CEBs and CSEBs is performed in several stages:

- Dig the soil to a depth of $50 \mathrm{~cm}$ at three different locations on each sampling site;

- Weigh with a scale the masses of soil sufficient for making the different specimens (Figure 1);

- Weigh the quantities of cement CPJ 35 at $4 \%$ and $8 \%$ of the soil mass, then proceed with dry mixing;

- Hydrate the whole (earth + cement) with about $12 \%$ water (Houben et al., 1996);

- Proceed to the compression of test piece with pression of 3MPa;

- Mold and remove the $4 \times 4 \times 16 \mathrm{~cm}^{3}, 4 \times 4 \times 4 \mathrm{~cm}^{3}$ and $8 \times 4 \times 2 \mathrm{~cm}^{3}$ specimens from the mold ;

- Wrap and leave the specimens to dry for 28 days.

\section{Procedures for the manufacturing of AEBs and ASEBs}

In order to manufacture AEBS and ASEBs, we need several stages:

- Dig the soil to a depth of $50 \mathrm{~cm}$ at three different locations on each site;

- Weigh the quantity of cement at $4 \%$ and $8 \%$ of the soil mass, then proceed with dry mixing;

- Hydrate the whole (earth + cement) with about $25 \%$ water (experiments in situ);

- Mold and remove the $4 \times 4 \times 16 \mathrm{~cm}^{3}$ specimens from the mold; 
- Dry the specimens during 28 days.

\subsubsection{Three-point bending compression}

Three-point bending tests were carried out on CEBs, CSEBs, AEBs and ASEBs specimens of $4 \times 4 \times 16 \mathrm{~cm}^{3}$ size, stabilized with $4 \%$ and $8 \%$ cement after 28 days using the electric press of brand impact. It weighs 5 tons, with a charge rate of $0.025 \mathrm{~mm} / \mathrm{s}$. The tests findings are collected from the electric press which indicates the maximum charge stress in MPa by each test.

\subsubsection{Simple compression tests}

Simple compression tests were carried out on CEBs, CSEBs AEB and ASEBs $4 \times 4 \times 4 \mathrm{~cm}^{3}$ specimens, stabilized with $4 \%$ and $8 \%$ cement after 28 days using the electric press of brand impact. It weighs 5 tons and have a charge rate of $0.03 \mathrm{~mm} / \mathrm{s}$.

\subsection{Absorption of CEBs, CSEBS, AEBs and ASEBS}

This test consists of immersing CEBs, CSEBs, AEBs and ASEBs of $4 \times 4 \times 16 \mathrm{~cm}^{3}$ in a container of water for 5 hours for the AEBs and ASEBs. However 5 days for the CEBs and CSEBs, then measuring the increase in the wet weight of the mass $m_{h}$ compared to the dry weight $m_{s}$ initially measured before immersion. A rapid depigmentation is observed after two hours of immersion on AEBs compared to CEBs.

\section{Results and discussion}

\subsection{Geotechnical properties}

The results of the geotechnical identification tests are presented in the following, including the complete particle size distribution, Atterberg limits and methylene blue test.

\section{Complete particle size distribution}

The three soil samples analysed are recommended for the manufacturing of CEBs according to the NF P94-056 and NF P94-057 standards, which define the range of the recommended spindle (Figure 2).

This spindle has been blacked out as a guide, only a small overflow of the GAD curve out of the low spindle is observed, but this does not have a significant influence. The proportions of gravel, sand, silt and clay grains in our samples are shown in the Table 1.

Table 1. Proportions of gravel, sand, silt and clay (MAI, BAM and GAD).

\begin{tabular}{|c|c|c|c|c|}
\cline { 2 - 5 } \multicolumn{1}{c|}{} & $\begin{array}{c}\% \text { GRAVEL } \\
\Phi>2000 \mu \mathrm{m}\end{array}$ & $\begin{array}{c}\% \\
\text { SAND } \\
20<\Phi<2000 \mu \mathrm{m}\end{array}$ & $\begin{array}{c}\% \\
\text { SILT } \\
2<\Phi<20 \mu \mathrm{m}\end{array}$ & $\begin{array}{c}\% \\
\text { CLAY } \\
\Phi \leq 2 \mu \mathrm{m}\end{array}$ \\
\hline MAI & 1,5 & 53,3 & 28,2 & 17 \\
\hline BAM & 14 & 48,2 & 14,3 & 23,5 \\
\hline GAD & 10,5 & 55,5 & 26 & 8 \\
\hline
\end{tabular}




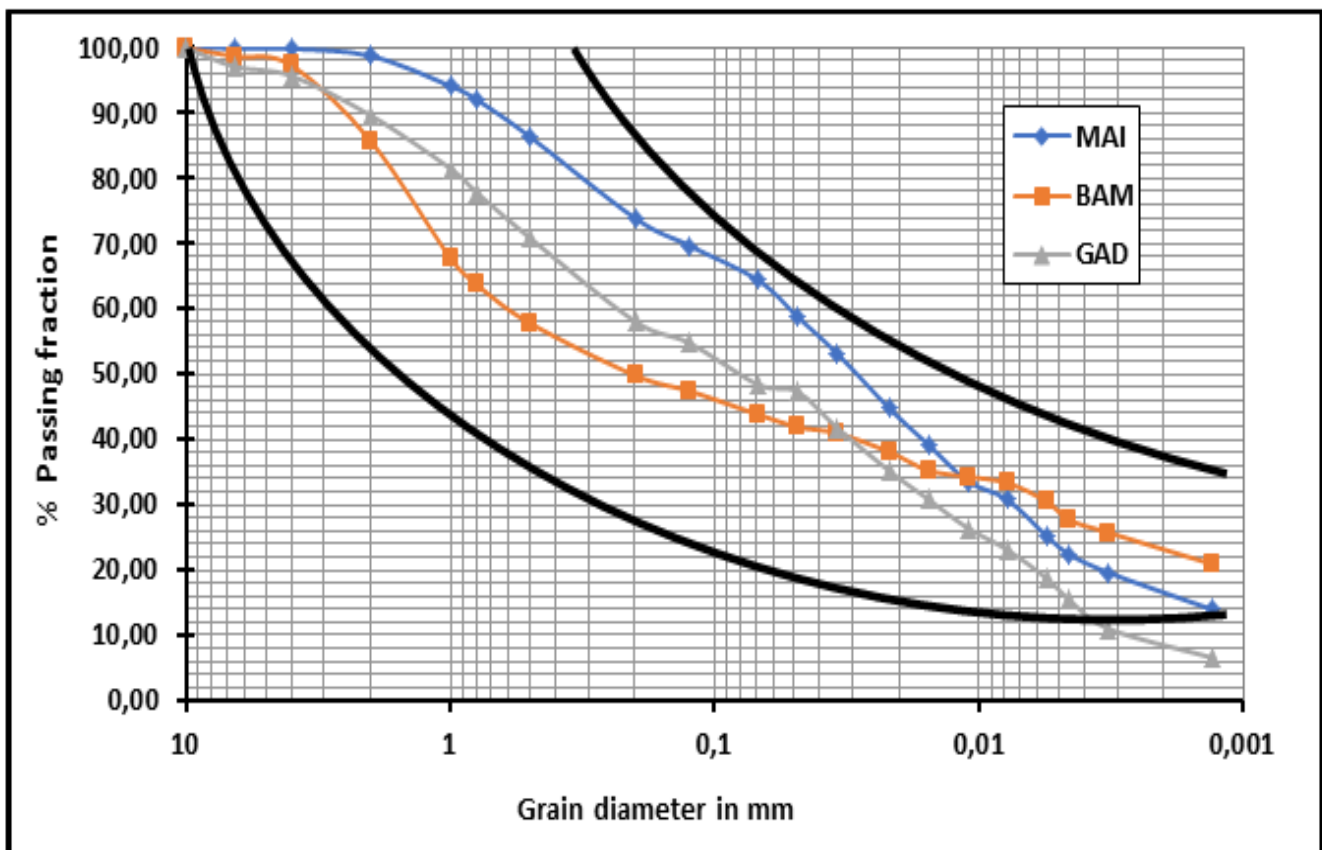

Fig. 2. Complete particle size distribution curve of MAI, BAM and GAD soil samples.

The triangular classification of soil, presents the ideal zone of the soils (Figure 3).

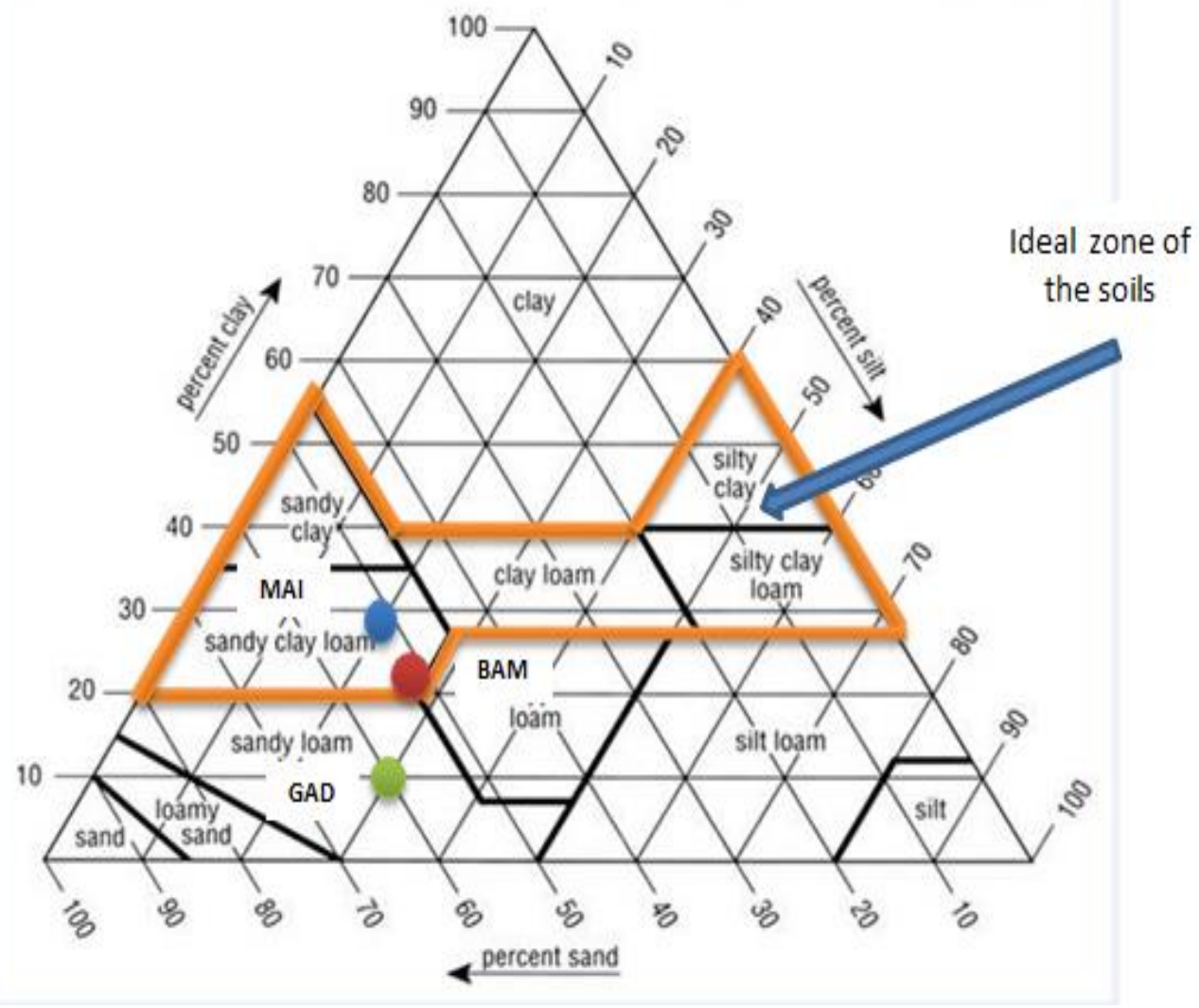

Fig. 3. Triangular classification of soil.

In addition, the GAD soil with the lowest clay content is the least resistant though the results are quite comparable. The most resistant is the BAM soil with higher clay content. The clay acts as a binder in the production of CEBs. The analysis of findings shows that, the highest proportions of 
grains in GAD samples are sand and silt, so we have sandy-silt type soils in out of the ideal zone. Whereas sand and clay are the highest proportions of grains in MAI and BAM, so we have sandysilt-clay in the ideal zone.

\section{Atterberg limits}

The liquidity and plastic limits and the plasticity index are summarised in table 2:

Table 2. Atterberg limits.

\begin{tabular}{|c|c|c|c|c|}
\hline \multicolumn{5}{|c|}{ Atterberg limits } \\
\hline \hline $\mathrm{N}^{0}$ & Sample & LL (\%) & PL (\%) & PI (\%) \\
\hline 1 & MAI & 44.3 & 26.1 & 18.6 \\
\hline 2 & BAM & 43.59 & 24.18 & 19.4 \\
\hline 3 & GAD & 44.66 & 24.33 & 20.32 \\
\hline
\end{tabular}

For the plasticity index (PI) of these samples ranged from 15 - 40, we have plastic soils according to the french standard NF 94-051.

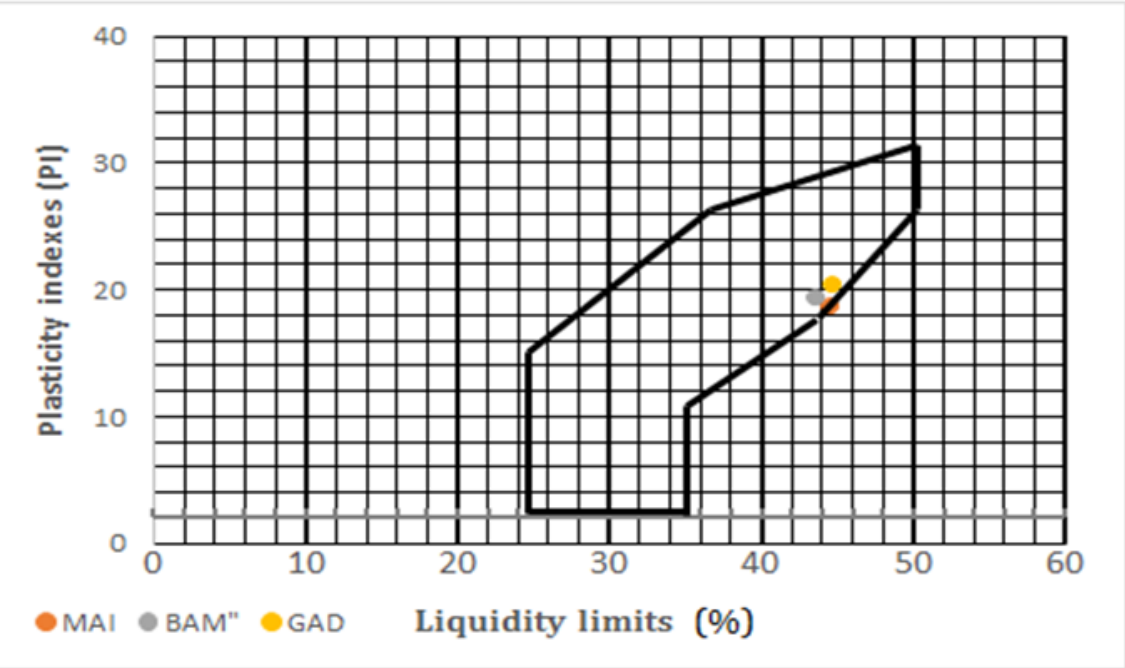

Fig. 4. Plasticity chart for soils specified in the XP P 13-901 standard.

Standard NF P 94-051 recommends for the manufacture of CEBs, soils whose properties belong to the spindle of the plasticity chart in Figure 4. This is the case for BAM and GAD samples, the MAI sample is at the limit of the recommended range.

\section{Methylene blue test}

The results of the methylene blue test are presented in Table 3.

Table 3. Methylene Blue value, Specific Surface Area (SP) and Blue Activity Index (Aсв)

\begin{tabular}{|c|c|c|c|c|}
\hline $\mathrm{N}^{0}$ & Sample & VBS $(\mathrm{g} / 100 \mathrm{~g})$ & $\mathrm{SP}_{\left(\mathrm{m}^{2} / \mathrm{g}\right)}$ & $\mathrm{A}_{\mathrm{CB}}$ \\
\hline 1 & MAI & 4.33 & 90.93 & 11.04 \\
\hline 2 & BAM & 2.5 & 52.5 & 07.09 \\
\hline 3 & GAD & 3.16 & 66.48 & 10.25 \\
\hline
\end{tabular}

The sample with the lowest clay content is that of BAM with $52.5 \mathrm{~m}^{2}$ per $1 \mathrm{~g}$. With regard to the blue activity index, all three samples are between 5 and 13, so we have soils with medium active clay levels according to the standard NF P 94 - 068 (Chrétien and Fabre, 2007). 


\subsection{Three-point bending compression strength of the CEBs and CSEBS}

The results of the maximum stresses of the three-point bending compression tests of the CEBs and CSEBs specimens are shown in the diagram in Figure 5.

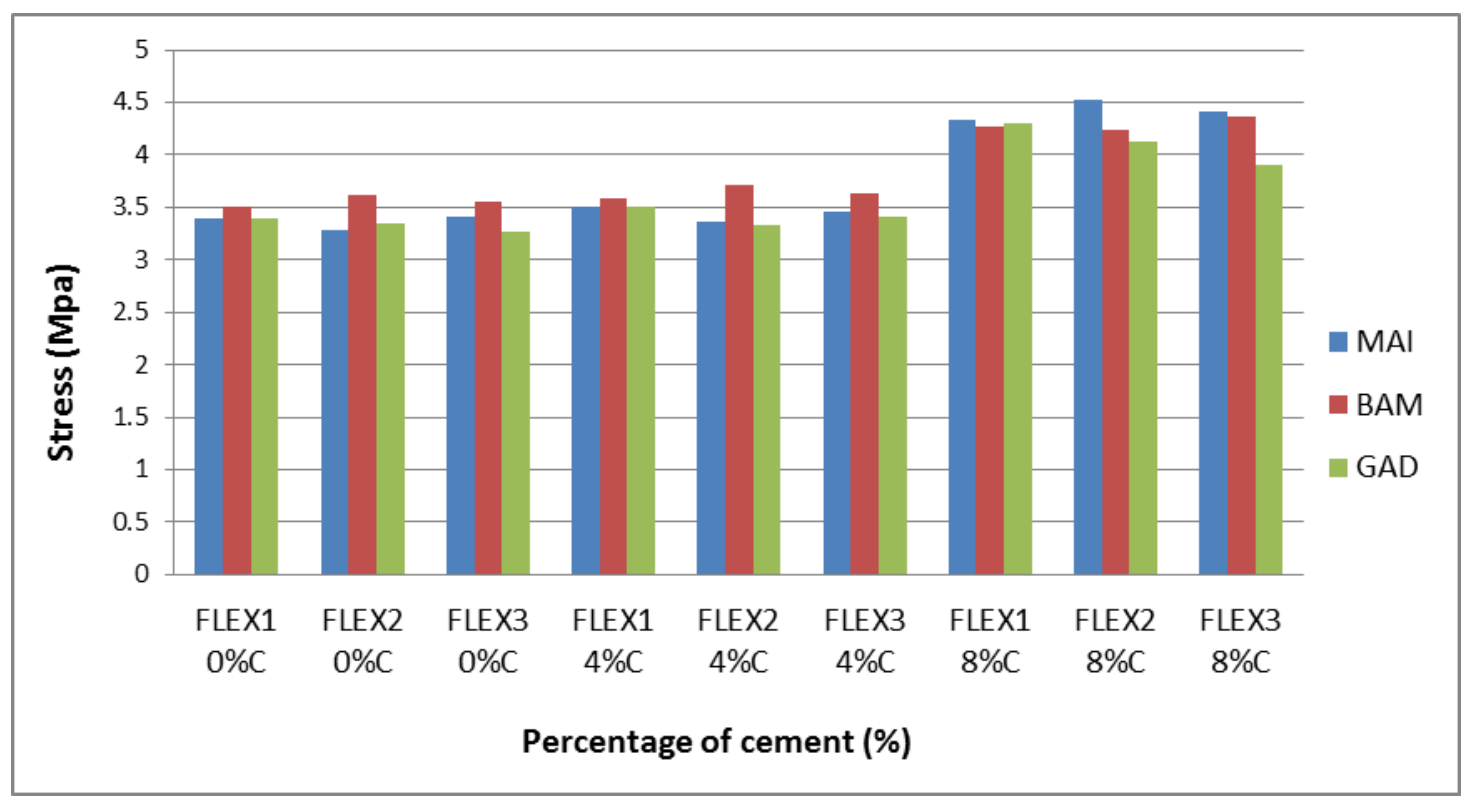

Fig. 5. Bending compression stress of the CEBs and CSEBs.

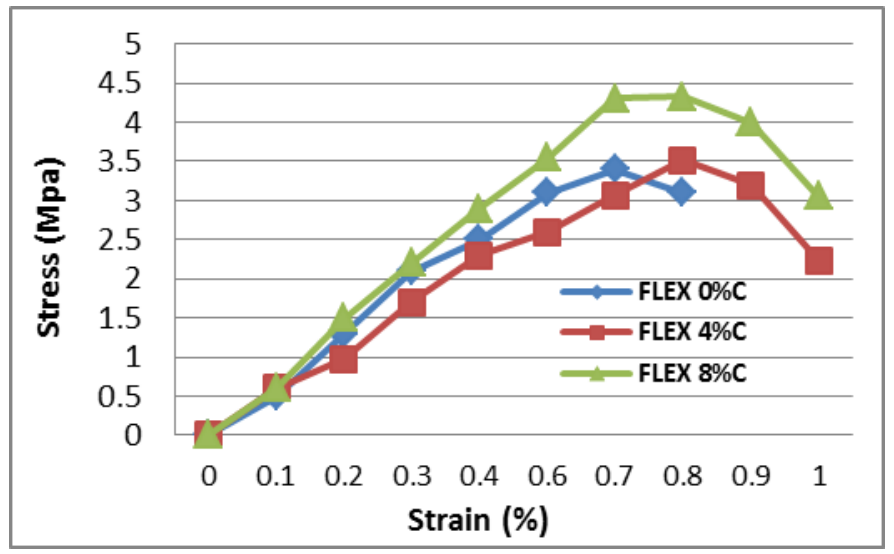

Fig. 6. Bending compression stress based on the strain of MAI.

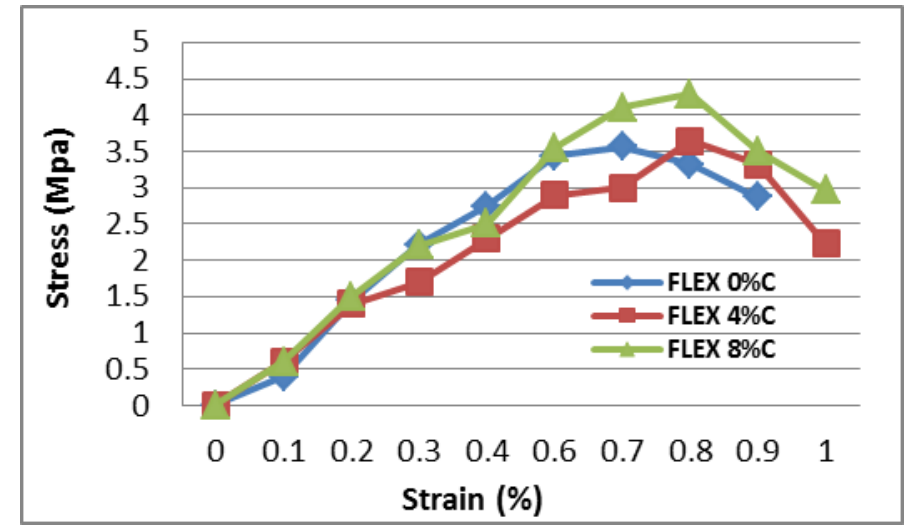

Fig. 7. Bending compression stress based on the strain of BAM. 


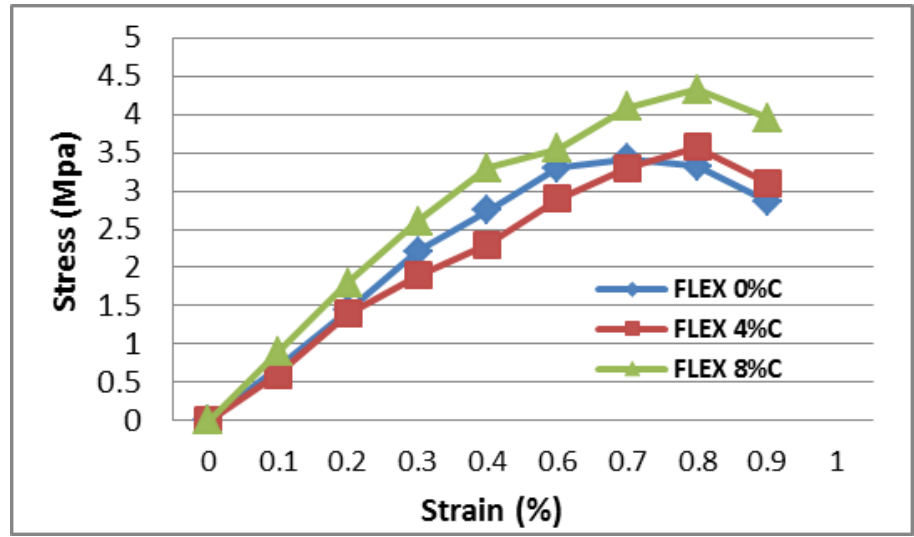

Fig. 8. Bending compression stress based on the strain of MAL.

Table 4. Medium bending compression stresses of the CEBs and CSEBs.

\begin{tabular}{|l|l|l|l|}
\hline Sample & Rmoy (0\%) & Rmoy (4\%) & Rmoy (8\%) \\
\hline MAI & 3,37 & 3,44 & 4,42 \\
\hline BAM & 3,56 & 3,64 & 4,29 \\
\hline GAD & 3,34 & 3,42 & 4,11 \\
\hline
\end{tabular}

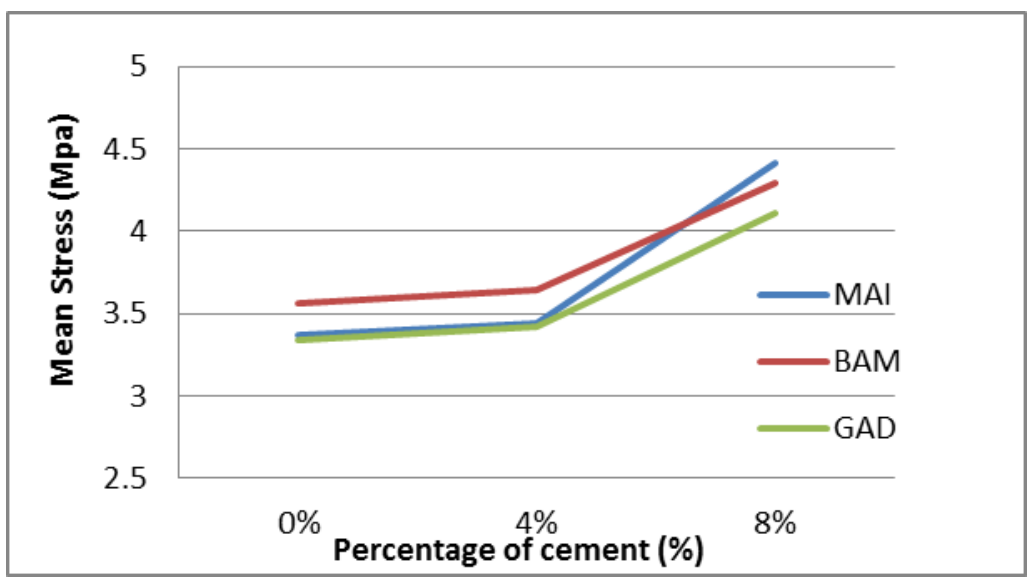

Fig. 9. Evolution of medium bending compression stresses of the CEBs and CSEBs.

We observe that dosages with $8 \%$ cement show a clear increase in the average bending stress of about $25 \%$ compared to the reference taken at $0 \%$ (Figure 5). This is due to the stabilization rate (clay + cement) which becomes greater than 30\% (Figures 6 to 8). Dosages of $4 \%$ produce a slight average increase of about $4.5 \%$. This is due to the stabilization rate (clay + cement) which becomes less than 30\% (Figures 6 to 8). Our experimental results show that the three-point bending compression strain values for $4 \%$ and $8 \%$ CSEBs are higher than those of Morel (Morel et al., 2002). Akpokodje examined the effect on the strength of soil with different cement contents. He found that, adding cement to a soil significantly increases its compressive strength (Akpokodje, 1985).

\subsection{Simple compression stress of the CEBs and CSEBS}

The results of the maximum stresses of the simple compression tests of the CEBs and CSEBs specimens are shown in Figure 10. 


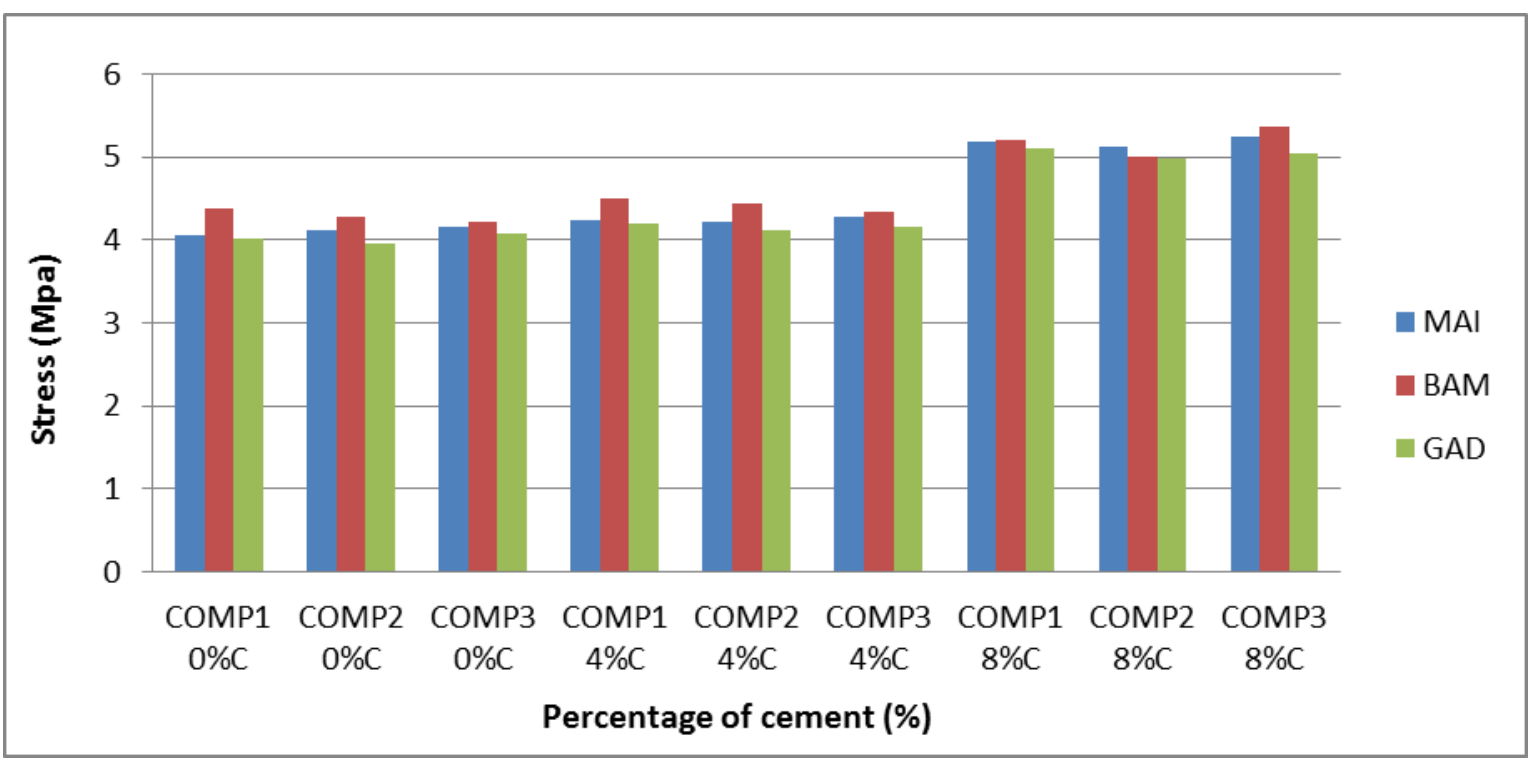

Fig. 10. Simple compression stress of the CSEBs and CEBs specimens.

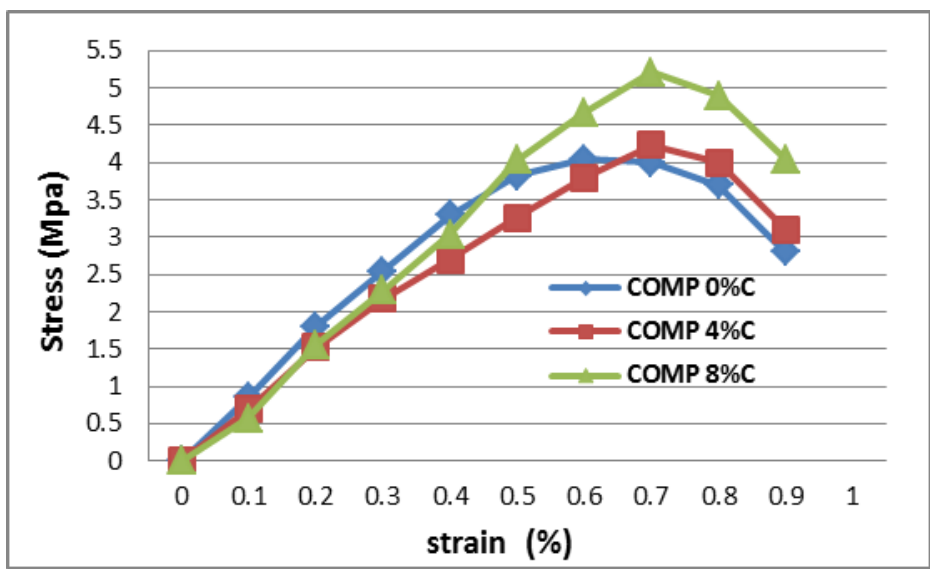

Fig. 11. Simple compression stress based on the strain of MAI.

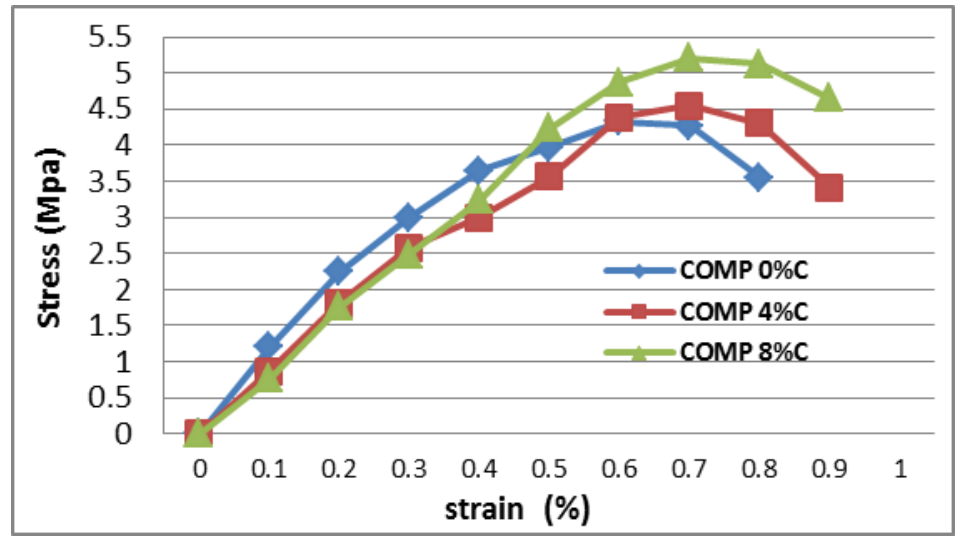

Fig. 12. Simple compression stress based on the strain of BAM. 


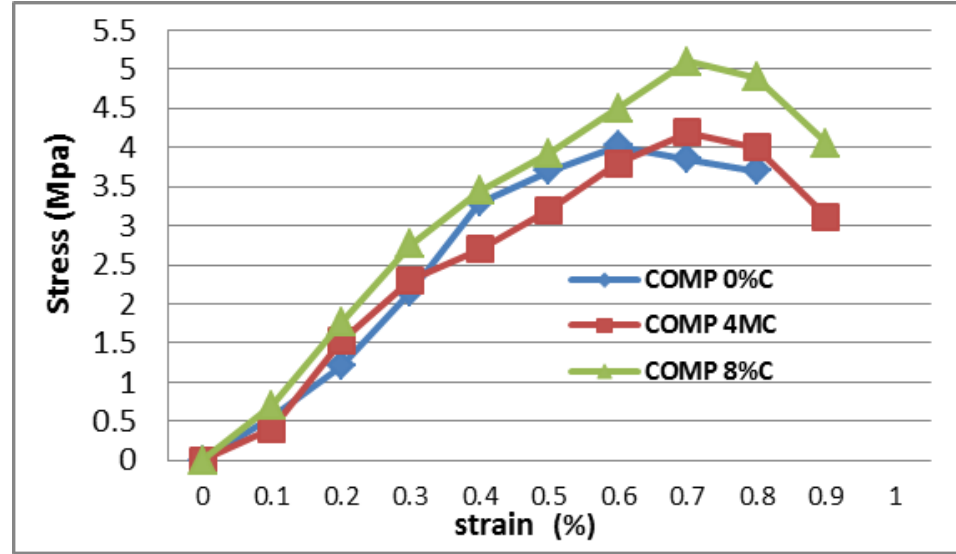

Fig. 13. Simple compression stress based on the strain of MAL.

Table 5. Medium simple compression stresses of the CSEBs and CEBs.

\begin{tabular}{|c|c|c|c|}
\hline Sample & Rcmoy (0\%) & Rcmoy (4\%) & Rcmoy (8\%) \\
\hline \hline MAI & 4,1 & 4,24 & 5,18 \\
\hline BAM & 4,3 & 4,43 & 5,2 \\
\hline GAD & 4,02 & 4,15 & 5,04 \\
\hline
\end{tabular}

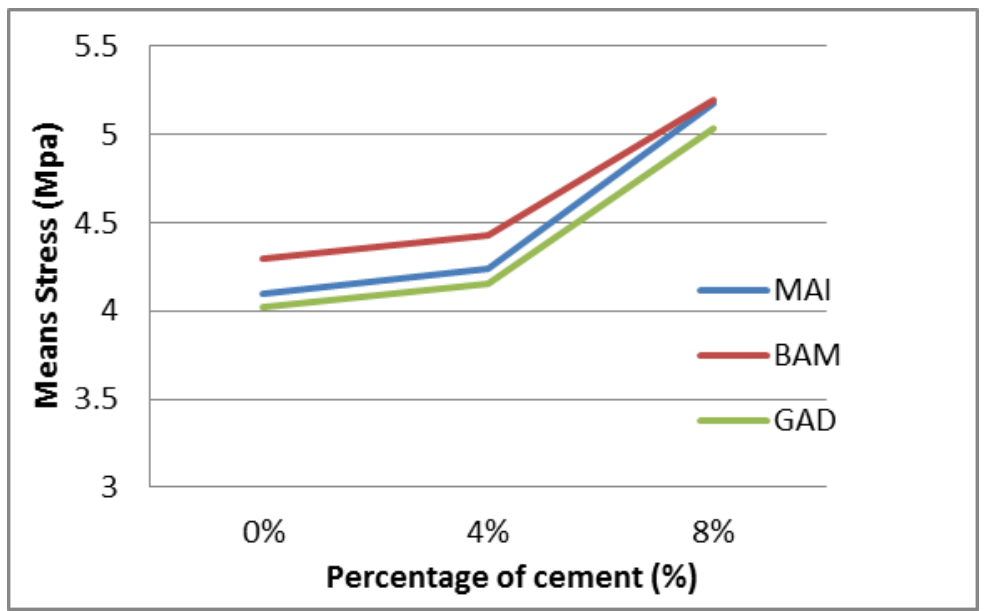

Fig. 14. Evolution of medium simple compression stresses of the CEBs and CSEBs.

The results of the maximum stresses of the simple compression tests of the CEBs and CSEBs specimens are shown in the diagram in Figure 10. Here, dosages with $8 \%$ cement show an increase in the average compression stress of about $25.55 \%$ compared to the reference taken at 0\% (Figure 10). These results are in agreement with those of Bahar (Bahar et al., 2004) who showed that the compression and tensile stress by splitting increases with increasing cement content. Our results are also in agreement with those obtained by Ntamack (Ntamack et al., 2012) on cement stabilization. They also show $4 \%$ higher stabilized simple compression stress values obtained by Bahar and Tran. Whereas our values are $8 \%$ lower as compared to Tran own and higher than that of Bahar (Bahar et al., 2004; Tran et al., 2018).

\subsection{Three-point bending compression strength of the AEBs and ASEBS}

The results of the maximum stresses of the three-point bending compression tests AEBs and ASEBs specimens are shown in the diagram in Figure 15. 


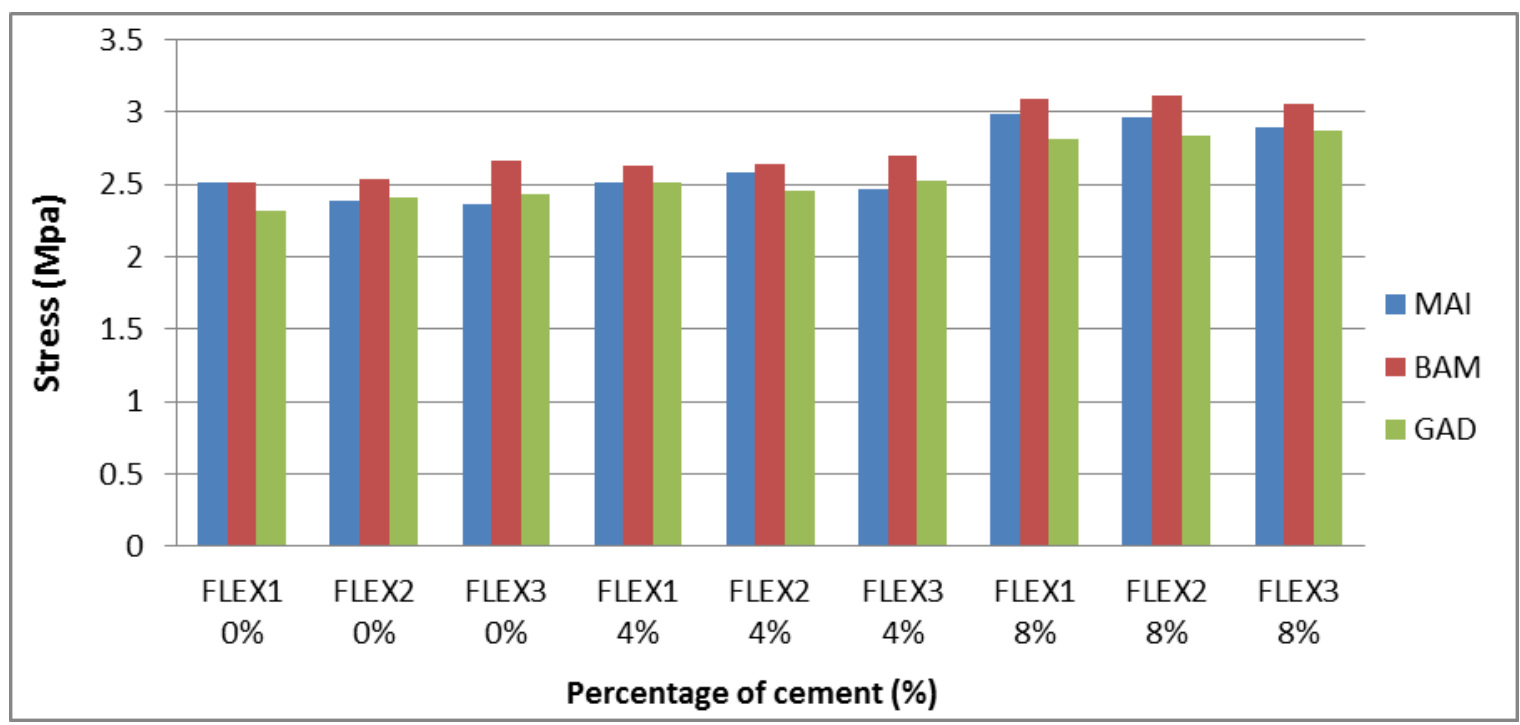

Fig. 15. Three-point bending compression stress of the AEBs and ASEBs.

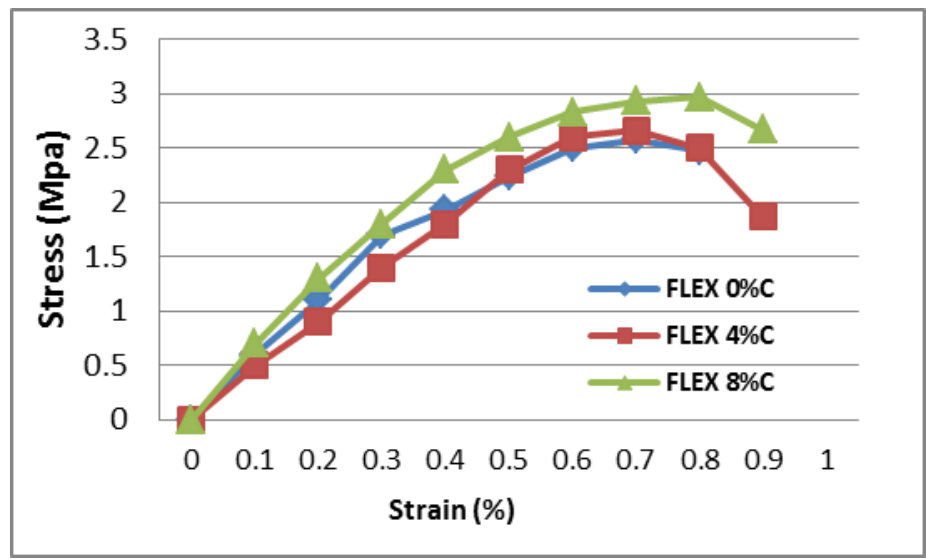

Fig. 16. Variation of the bending compression stress with the strain of MAI $(0 \%, 4 \%$ and $8 \%)$.

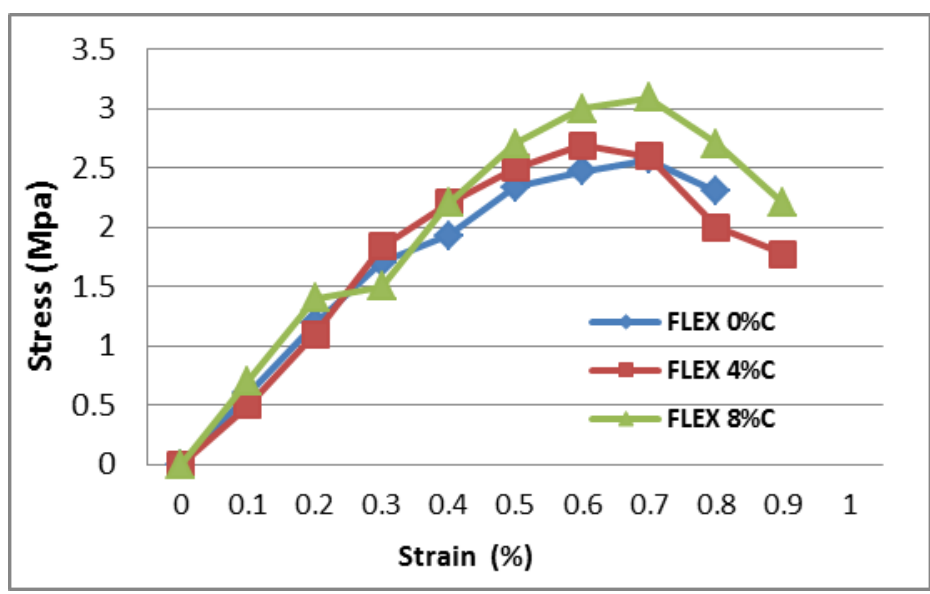

Fig. 17. Variation of the bending compression stress with the strain of BAM $(0 \%, 4 \%$ and $8 \%)$. 


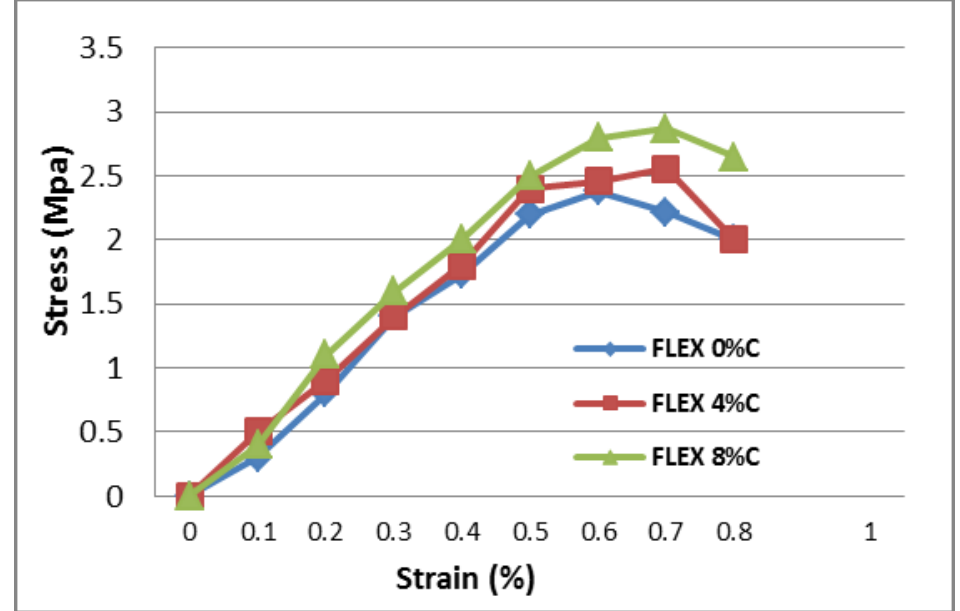

Fig. 18. Variation of the bending compression stress with the strain of GAD $(0 \%, 4 \%$ and $8 \%)$.

Table 6. Medium bending compression stresses of the AEBs and ASEBs.

\begin{tabular}{|c|c|c|c|}
\hline Sample & Rmoy (0\%) & Rmoy (4\%) & Rmoy(8\%) \\
\hline \hline MAI & 2,42 & 2,52 & 2,95 \\
\hline BAM & 2,58 & 2,66 & 3,09 \\
\hline GAD & 2,39 & 2,5 & 2,84 \\
\hline
\end{tabular}

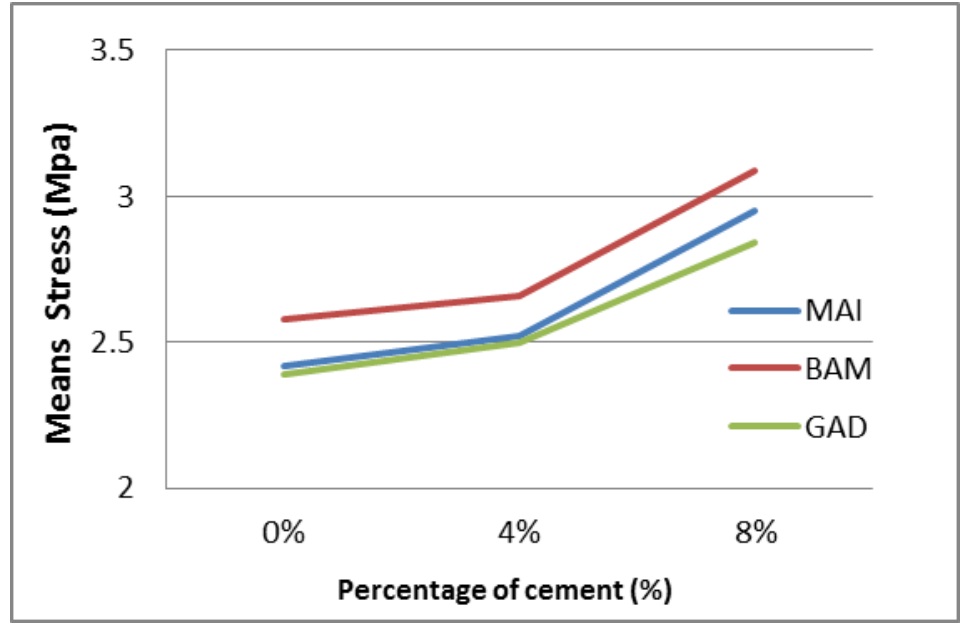

Fig. 19. Evolution of medium bending compression stresses of the AEBs and ASEBs.

Here, dosages with $8 \%$ cement show an increase in the average bending stress of about $23.02 \%$ compared to the reference taken at $0 \%$ (Figure 15). This is due to the stabilization rate (clay + cement) which becomes greater than $30 \%$ (Figures 16 to 18). Dosages of 4\%, produces a slight average increase of about $5.49 \%$. This is due to the stabilization rate (clay + cement) which becomes is less than $30 \%$ (Figures 16 to 18).

\subsection{Simple compression strength on AEBs and ASEBS}

The results of the maximum stresses of the simple compression tests AEB and ASEBs at $4 \%$ and $8 \%$ on $4 \times 4 \times 4 \mathrm{~cm}^{3}$ specimens are shown in the diagram in Figure 20. 


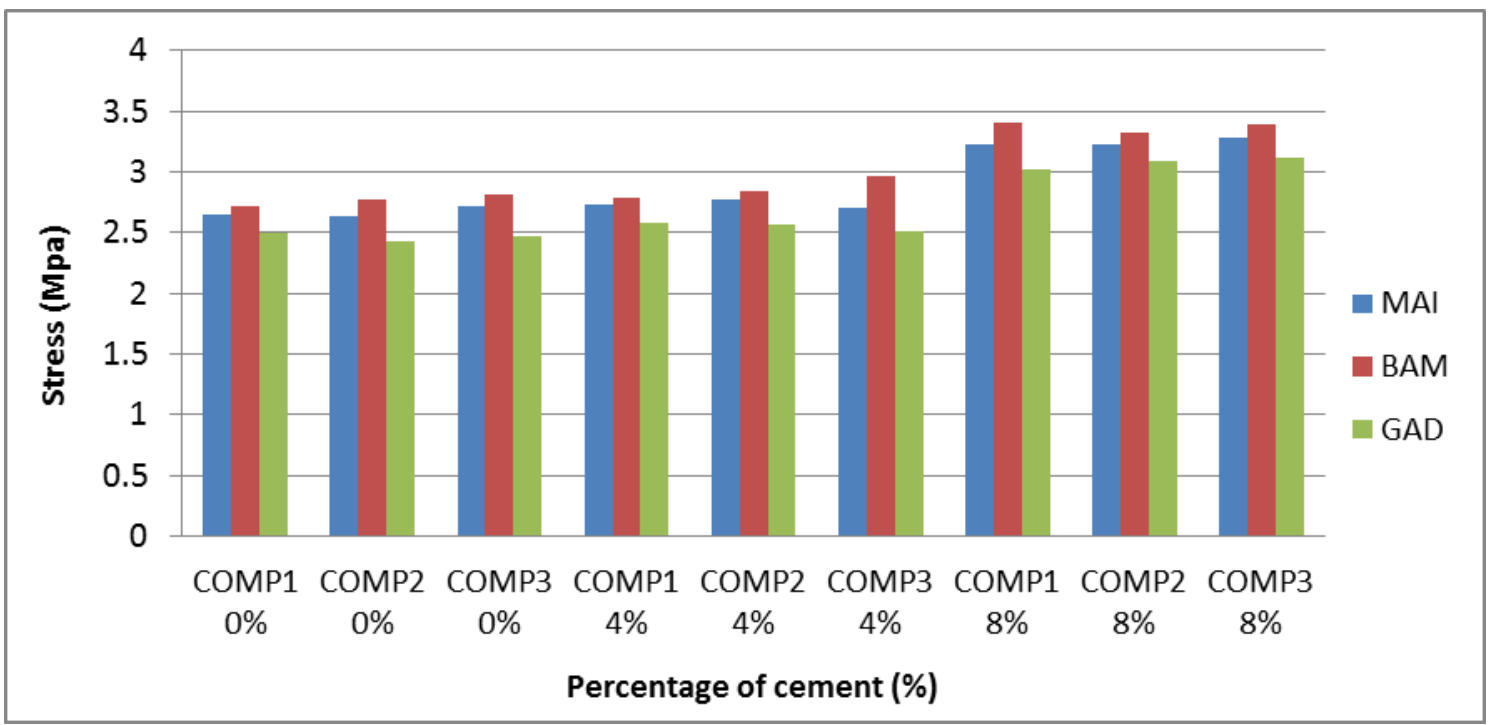

Fig. 20. Simple compression stress of AEBs and ASEBs.

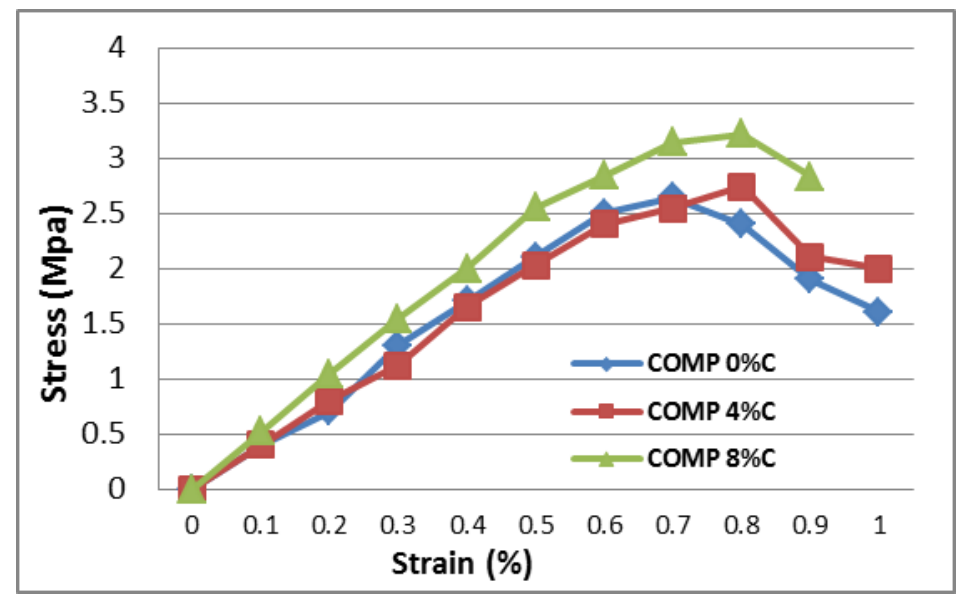

Fig. 21. Variation of simple compression stress of the strain of MAI.

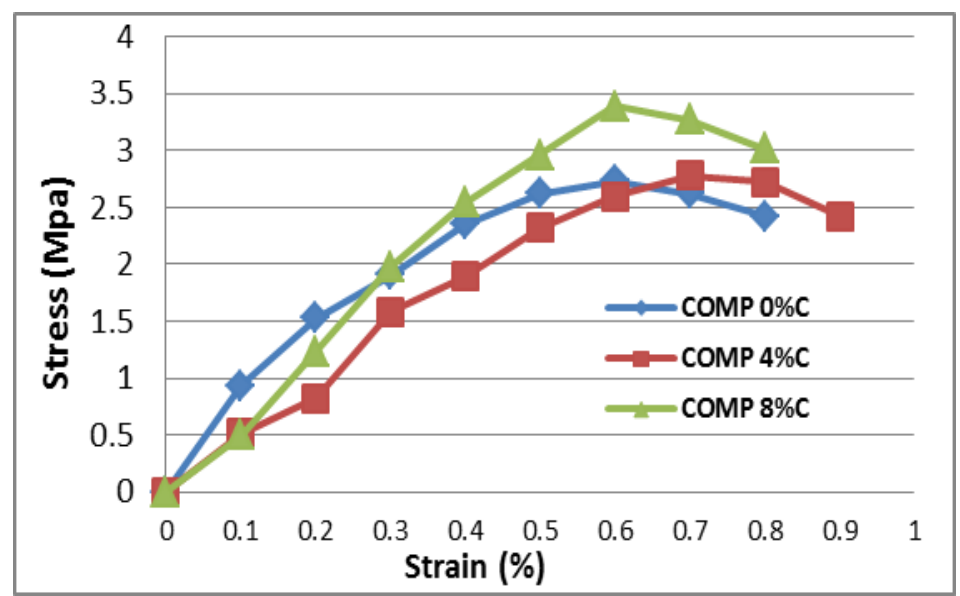

Fig. 22. Variation of simple compression stress of the strain of BAM. 


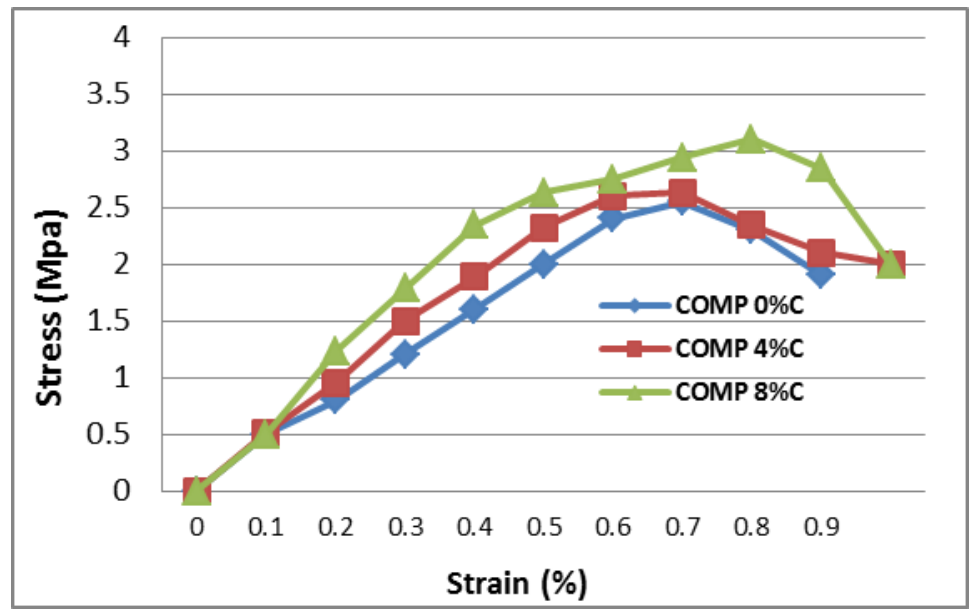

Fig. 23. Variation of simple compression stress of the strain of GAD.

Table 7. Medium simple compression stresses of AEBs and ASEBs.

\begin{tabular}{|c|c|c|c|}
\hline Sample & Rcmoy (0\%) & Rcmoy (4\%) & Rcmoy (8\%) \\
\hline \hline MAI & 2,67 & 2,74 & 3,24 \\
\hline BAM & 2,77 & 2,86 & 3,37 \\
\hline GAD & 2,47 & 2,55 & 3,07 \\
\hline
\end{tabular}

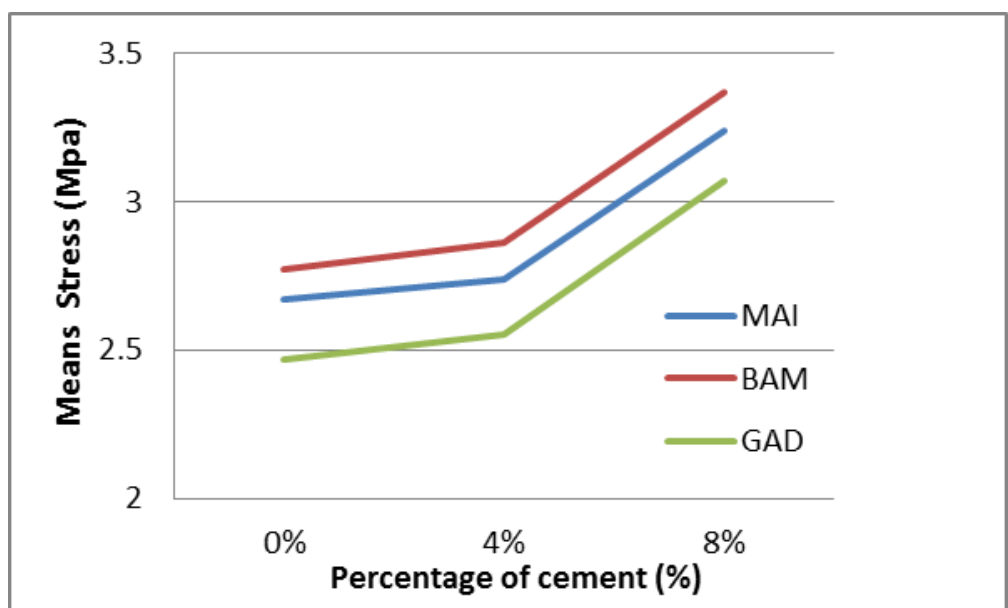

Fig. 24. Evolution of medium simple compression stresses of the AEBs and ASEBs.

The results of the maximum stresses of the simple compression tests AEBs, ASEBs at $4 \%$ and $8 \%$ on $4 \times 4 \times 4 \mathrm{~cm}^{3}$ specimens are shown in the diagram in Figure 20. Here, dosages with $8 \%$ cement show an increase in the average bending stress of about $22.85 \%$ compared to the reference taken at $0 \%$ (Figure 20). This is due to the stabilization rate (clay + cement) which becomes greater than 30\% (Figures 21 to 23). The dosages of 4\% produce a slight average increase of about $3.14 \%$. This is due to the stabilization rate (clay + cement) which becomes is less than $30 \%$ (Figures 21 to 23). Our results show higher values of simple compression stress stabilized at $0 \%$ and $8 \%$ cement compared to the studies of Dao (Dao et al., 2018). Nevertheless, our values are $4 \%$ lower than the results of the latter.

\subsection{Absorption rates of CEBs and CSEBS}

Results obtained by immersing our CEBs and CSEBs specimens for 5 days. These specimens CEBs and CSEBs at 4\% and 8\% respectively and are shown in Figures 25 to 27. 


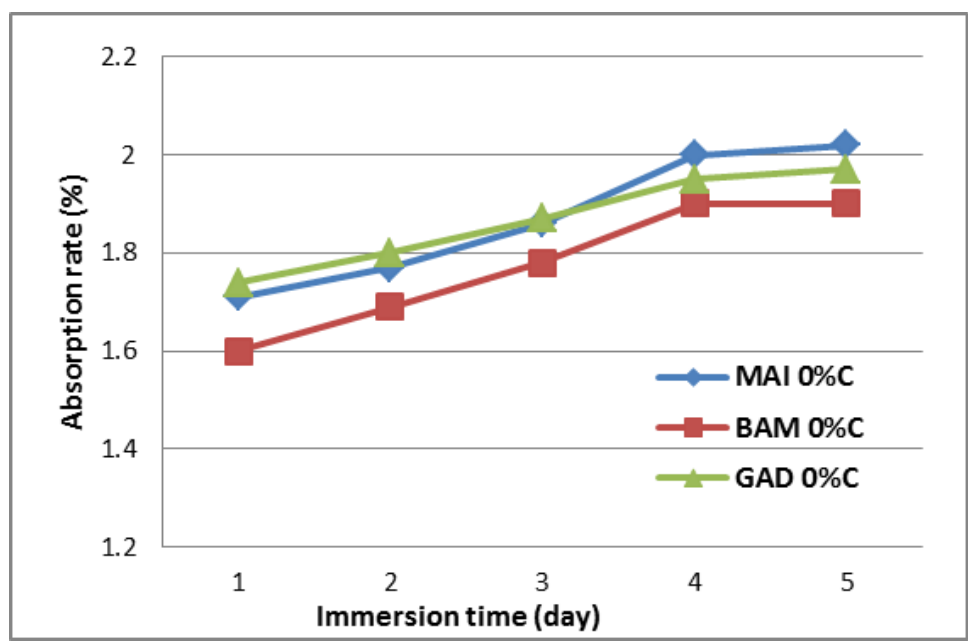

Fig. 25. Absorption rate of CEBs at $0 \%$.

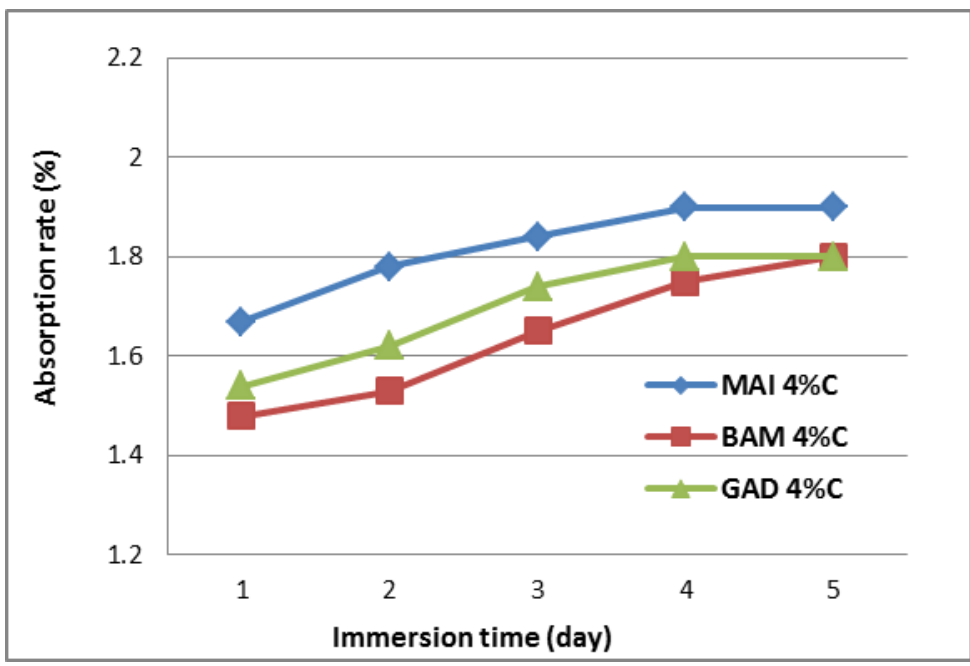

Fig. 26. Absorption rate of CSEBs at $4 \%$.

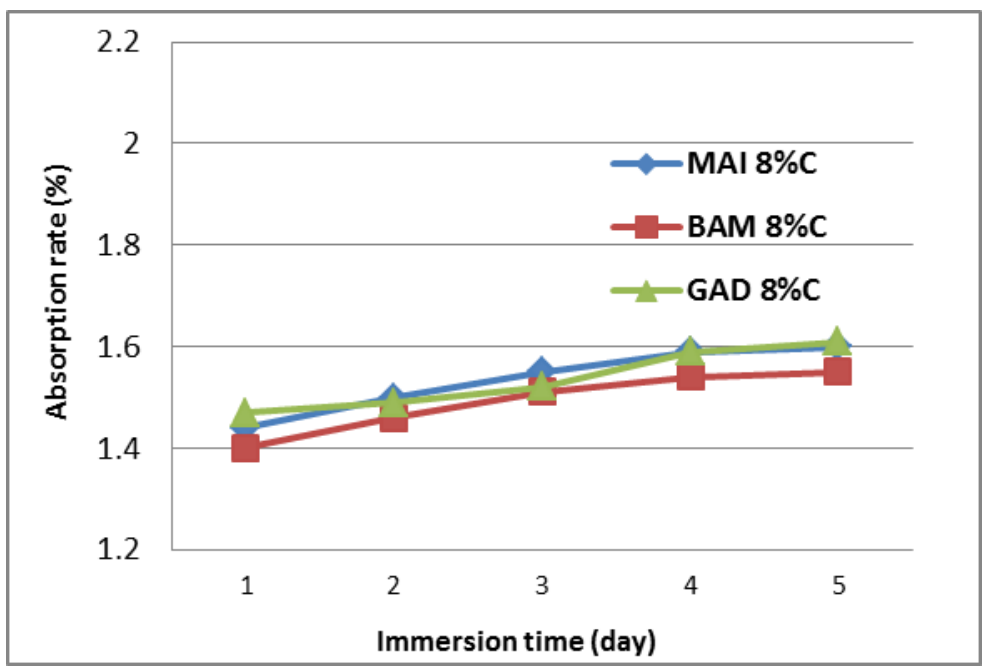

Fig. 27. Absorption rate of CSEBs at $8 \%$.

We can observe how immersion time and cement dosage levels influence the rate of absorption of the CEBs. A clear decrease in the rate of absorption is obtained when the dosage of stabilizer is increased (Figures 25 to 27), thus cement stabilization considerably reduces the porosity of CSEBs. These findings corroborate Meukam (Meukam al. 2004) studies, which show that the 
addition of cement has a beneficial effect on the water absorption of stabilized earth blocks. Indeed, he found that the rate of water absorption decreases as the cement content increases. This results in the interaction between clay and cement. The increasing of the cohesive strength of the particles reduces the porosity.

\subsection{Absorption rates of AEBs and ASEBS}

The results were obtained by immersing our AEBs and ASEBs specimens in water for 5 hours. This happens because of their high sensitivity to water, which causes them to depigment rapidly after a few hours of immersion, because of their high porosity. These specimens AEBs at $0 \%$ and ASEBs at 4\% and 8\% respectively are shown in Figures 28 to 30.

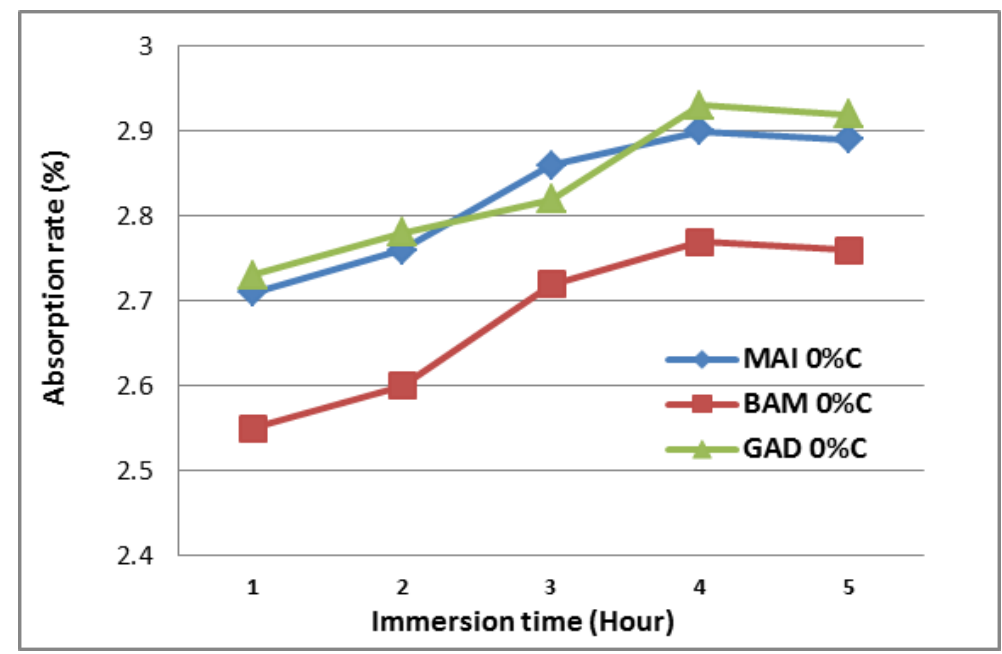

Fig. 28. Absorption rate of AEBs at $0 \% \mathrm{C}$.

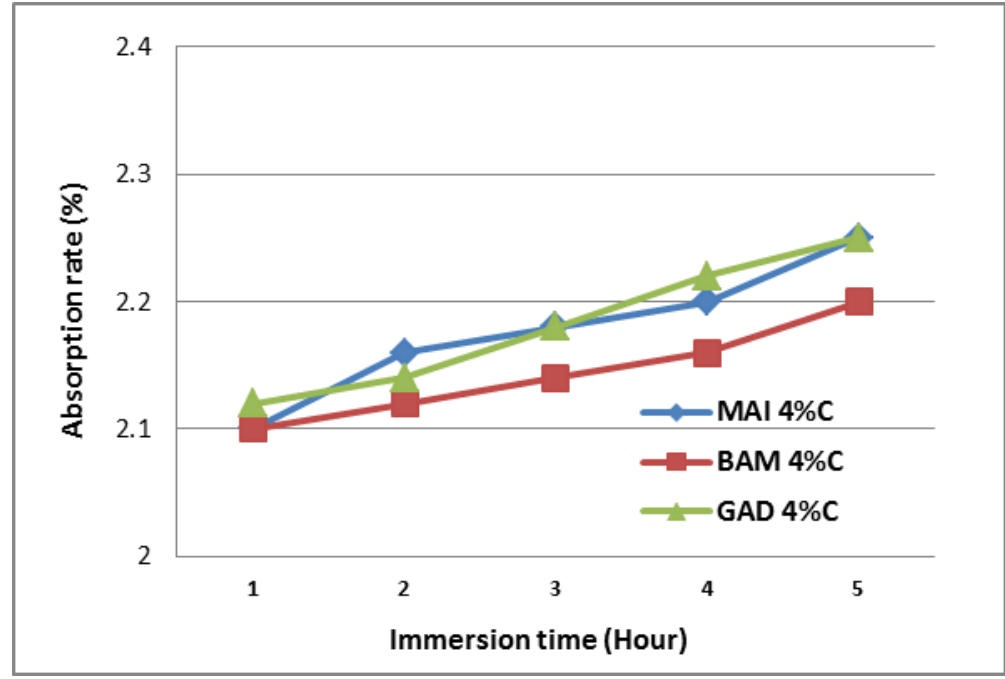

Fig. 29. Absorption rate of ASEBs at 4\%C.

In addition, the cement dosage levels also influence the absorption rate of AEBs, with a decrease in absorption rate being observed when the cement dosage increases, in Figures 28 to 30 . The same reaction is observed as in ASEBs, with a water absorption rate that decreases with increasing cement, but with a better result at $8 \%$ compared to $4 \%$ cement. We can observe how immersion time and cement dosage levels influence the rate of absorption of the CEBs. 


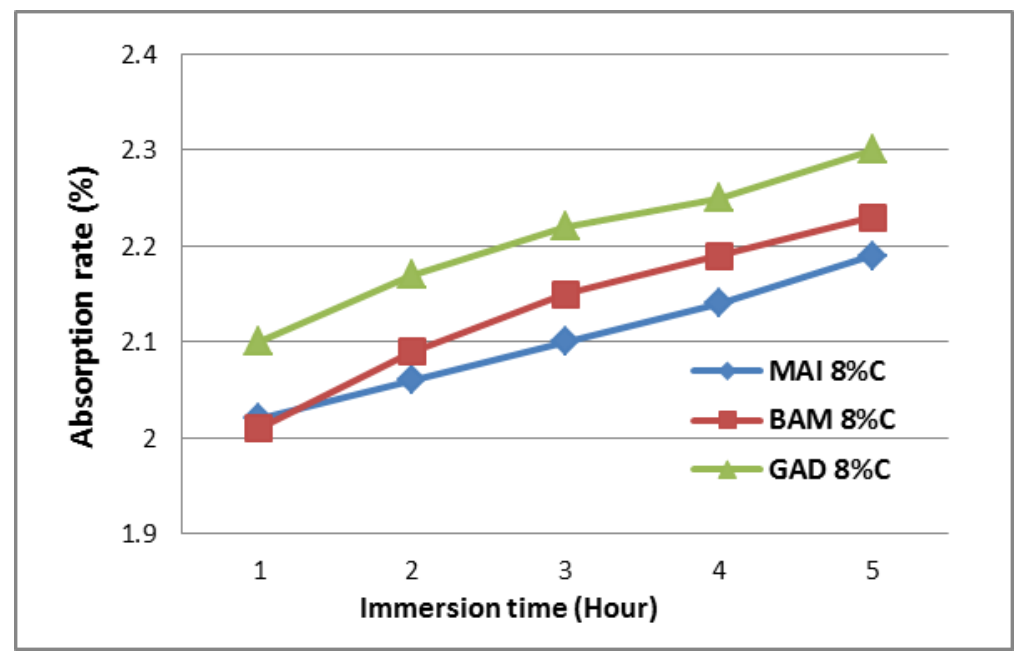

Fig. 30. Absorption rate of ASEBs at 8\%C.

\subsection{Medium stresses comparison between CEBs, CSEBs, AEBs and ASEBs}

The results of the means stress comparison of the simple compression and the three-point bending compression between CEBs, CSEBs, AEBs and ASEB are present in the tables 8 to 15.

\subsubsection{Means stress comparison of the bending compression strength between CSEs, CSEBs, AEBs and ASEBS}

The results of the medium stresses comparison of the three-point bending compression between CEBs, CSEBs, AEBs and ASEBs are present in the Tables 8 to 11.

Table 8. Medium bending compression stresses of CSEs, CSEBs and AEBs, ASEBs

\begin{tabular}{|c|c|c|c|c|c|c|c|c|c|c|}
\hline \multicolumn{4}{|c|}{ Proportions } & AEBs & CEBs & ASEBs & CSEBs & ASEBs & CSEBs \\
\hline $\mathrm{N}^{0}$ & Soil & Gravel +Sand & Silt & Clay & \multicolumn{2}{c|}{ Rcm $(0 \%)$} & \multicolumn{2}{c|}{ Rcm $(4 \%)$} & \multicolumn{2}{c|}{ Rcm (8\%) } \\
\hline 1 & MAI & 54,8 & 28,2 & 17 & 2,42 & 3,37 & 2,52 & 3,44 & 2,95 & 4,42 \\
\hline 2 & BAM & 62,2 & 14,3 & 23,5 & 2,58 & 3,56 & 2,66 & 3,64 & 3,09 & 4,29 \\
\hline 3 & GAD & 66 & 26 & 8 & 2,39 & 3,34 & 2,50 & 3,42 & 2,84 & 4,11 \\
\hline
\end{tabular}

Table 9. The gain of the medium bending compression stresses of CEBs and AEBs at $0 \%$.

\begin{tabular}{|c|c|c|c|c|c|c|c|}
\hline \multicolumn{5}{|c|}{ Proportions } & AEBs & CEBs & CEBs/AEBs \\
\hline $\mathrm{N}^{0}$ & Soil & Gravel + Sand & Silt & Clay & Rcm $(0 \%)$ & Rcm $(0 \%)$ & Gain \\
\hline 1 & MAI & 54,8 & 28,2 & 17 & 2,42 & 3,37 & $39 \%$ \\
\hline 2 & BAM & 62,2 & 14,3 & 23,5 & 2,58 & 3,56 & $38 \%$ \\
\hline 3 & GAD & 66 & 26 & 8 & 2,39 & 3,34 & $40 \%$ \\
\hline
\end{tabular}

Table 10. The gain of the medium bending compression stresses of CSEBs and ASEBs at $4 \%$.

\begin{tabular}{|c|c|c|c|c|c|c|c|}
\hline \multicolumn{5}{|c|}{ Proportions } & AEBs & CEBs & CEBs/AEBs \\
\hline N $^{0}$ & Soil & Gravel + Sand & Silt & Clay & Rcm (4\%) & Rcm (4\%) & Gain \\
\hline 1 & MAI & 54,8 & 28,2 & 17 & 2,52 & 3,44 & $37 \%$ \\
\hline 2 & BAM & 62,2 & 14,3 & 23,5 & 2,66 & 3,64 & $37 \%$ \\
\hline 3 & GAD & 66 & 26 & 8 & 2,50 & 3,42 & $37 \%$ \\
\hline
\end{tabular}

Table 11. The gain of the medium bending compression stresses of CSEBs and ASEBs at $8 \%$.

\begin{tabular}{|c|c|c|c|c|c|c|c|}
\hline \multicolumn{5}{|c|}{ Proportions } & AEBs & CEBs & CEBs/AEBs \\
\hline N0 & Soil & Gravel + Sand & Silt & Clay & Rcm $(8 \%)$ & Rcm (8\%) & Gain \\
\hline 1 & MAI & 54,8 & 28,2 & 17 & 2,95 & 4,42 & $50 \%$ \\
\hline 2 & BAM & 62,2 & 14,3 & 23,5 & 3,09 & 4,29 & $39 \%$ \\
\hline 3 & GAD & 66 & 26 & 8 & 2,84 & 4,11 & $45 \%$ \\
\hline
\end{tabular}


The results were obtained for three-point bending compression for a cement dosage of $8 \%$, there is also an increase in stress of about $45 \%$ for the CSEBs compared to the ASEBs. On the other hand, for a dosage of $4 \%$, we observe a slight increase in stress by three-point bending compression of around 37\% for CSEBs compared to the ASEBs. For a dosage of $0 \%$, we observe a slight increase in stress by the three-point bending compression of around 39\% for CEBs compared to the AEBs.

\subsubsection{Means stress comparison of the simple compression stress between CEBs, CSEBs, AEBs and ASEBS}

The results of the medium stresses comparison of the simple compression between CEBs, CSEBs, AEBs and ASEBs are present in Tables 12 to 15.

Table 12. Medium simple compression stresses of CEBs, CSEBs, AEBs and ASEBs.

\begin{tabular}{|c|c|c|c|c|c|c|c|c|c|c|}
\hline \multicolumn{4}{|c|}{ Proportions } & AEBs & CEBs & ASEBs & CSEBs & ASEBs & CSEBs \\
\hline $\mathrm{N}^{0}$ & Soil & Gravel +Sand & Silt & Clay & \multicolumn{2}{c|}{ Rcm $(0 \%)$} & \multicolumn{2}{c|}{ Rcm $(4 \%)$} & \multicolumn{2}{c|}{ Rcm (8\%) } \\
\hline 1 & MAI & 54,8 & 28,2 & 17 & 2,67 & 4,10 & 2,74 & 4,24 & 3,24 & 5,18 \\
\hline 2 & BAM & 62,2 & 14,3 & 23,5 & 2,77 & 4,30 & 2,86 & 4,43 & 3,37 & 5,20 \\
\hline 3 & GAD & 66 & 26 & 8 & 2,47 & 4,02 & 2,55 & 4,15 & 3,07 & 5,04 \\
\hline
\end{tabular}

Table 13. The gain of the medium simple compression stresses of CEBs and AEBs at $0 \%$.

\begin{tabular}{|c|c|c|c|c|c|c|c|}
\hline \multicolumn{5}{|c|}{ Proportions } & AEBs & CEBs & CEBs/AEBs \\
\hline $\mathrm{N}^{0}$ & Soil & Gravel + Sand & Silt & Clay & Rcm $(0 \%)$ & Rcm $(0 \%)$ & Gain \\
\hline 1 & MAI & 54,8 & 28,2 & 17 & 2,67 & 4,10 & $54 \%$ \\
\hline 2 & BAM & 62,2 & 14,3 & 23,5 & 2,77 & 4,30 & $55 \%$ \\
\hline 3 & GAD & 66 & 26 & 8 & 2,47 & 4,02 & $63 \%$ \\
\hline
\end{tabular}

Table 14. The gain of the medium simple compression stresses of CSEBs and ASEBs at 4\%.

\begin{tabular}{|c|c|c|c|c|c|c|c|}
\hline \multicolumn{4}{|c|}{ Proportions } & AEBs & CEBs & CEBs/AEBs \\
\hline $\mathrm{N}^{0}$ & Soil & Gravel + Sand & Silt & Clay & Rcm $(4 \%)$ & Rcm $(4 \%)$ & Gain \\
\hline 1 & MAI & 54,8 & 28,2 & 17 & 2,74 & 4,24 & $55 \%$ \\
\hline 2 & BAM & 62,2 & 14,3 & 23,5 & 2,86 & 4,43 & $55 \%$ \\
\hline 3 & GAD & 66 & 26 & 8 & 2,55 & 4,15 & $63 \%$ \\
\hline
\end{tabular}

Table 15. The gain of the medium simple compression stresses of CSEBs and ASEBs at $8 \%$.

\begin{tabular}{|c|c|c|c|c|c|c|c|}
\hline \multicolumn{5}{|c|}{ Proportions } & AEBs & CEBs & CEBs/AEBs \\
\hline $\mathrm{N}^{0}$ & Soil & Gravel + Sand & Silt & Clay & Rcm $(8 \%)$ & Rcm $(8 \%)$ & Gain \\
\hline 1 & MAI & 54,8 & 28,2 & 17 & 3,24 & 5,18 & $60 \%$ \\
\hline 2 & BAM & 62,2 & 14,3 & 23,5 & 3,37 & 5,20 & $54 \%$ \\
\hline 3 & GAD & 66 & 26 & 8 & 3,07 & 5,04 & $64 \%$ \\
\hline
\end{tabular}

The findings indicate that dosing with $8 \%$ cement results in a clear increase in compression stress of approximately $59 \%$ for CSEBs compared to the ASEBs. On the other hand, for a dosage of $4 \%$, we observe a slight increase in stress by simple compression of around $58 \%$ for CSEBs compared to the ASEBs. For a dosage of $0 \%$, we observe a slight increase in stress by simple compression of around $57 \%$ for CEBs compared to the AEBs.

Compressed and stabilized earth brings double the benefits of compression and stabilization. Stabilisation with cement a blend of limestone and clay - can increase the resistance of the earth block by at least $20 \%$. The cement content in the AEBs can be increased to the desired value for a given strength. However, when a certain proportion is added, the resistance of the earth block hardly varies. Hence, compressed earth is less expensive and requires a manual press which can be easily done. The resistance is enhanced by about $40 \%$ in bending and $58 \%$ in simple compression that is two to three times greater than with the addition of cement. 


\section{Conclusions}

This study aimed at evaluating the effects of cement stabilization on the mechanical performance of compressed stabilized earth blocks (CSEBs) and adobe stabilized earth bricks (ASEBs). To this end, the geotechnical properties of the sampled soils were analysed, namely dry particle size distribution after washing, particle size distribution by sedimentometry, Atterberg limits (LL, PL and PI), methylene blue test and the preparation of specimens $\left(4 \times 4 \times 16 \mathrm{~cm}^{3}\right.$, $4 \times 4 \times 4 \mathrm{~cm}^{3}$ and $\left.2 \times 4 \times 8 \mathrm{~cm}^{3}\right)$ with different levels of cement (stabilizer) proportions $(0 \%, 04 \%$, $08 \%$ ). The findings indicate that dosing with $8 \%$ cement results in a clear increase in compression stress of approximately $25.55 \%$ for CSEBs compared to the reference set at $0 \%$ and $22.85 \%$ for ASEBs.

On the other hand, for a dosage of $4 \%$, we observe a slight increase in stress by simple compression of around 3.26\% for CSEBs and 3.14\% for ASEBs. For three-point bending compression for a cement dosage of $8 \%$, there is also an increase in stress of about $25 \%$ for the CSEBs compared to the reference taken at $0 \%$ and $23.02 \%$ for the ASEBs. However, we observe a slight increase in stress at $4 \%$ by simple compression of around $4.5 \%$ for CSEBs and $5.49 \%$ for ASEBs. The results were obtained for three-point bending compression for a cement dosage of $8 \%$, there is also an increase in stress of about $45 \%$ for the CSEBs compared to the ASEBs. On the other hand, for a dosage of $4 \%$, we observe a slight increase in stress by three-point bending compression of around $37 \%$ for CSEBs compared to the ASEBs. For a dosage of $0 \%$, we observe a slight increase in stress by simple compression of around 39\% for CEBs compared to the AEBs. The findings indicate that dosing with $8 \%$ cement results in a clear increase in compression stress of approximately 59\% for CSEBs compared to the ASEBs. On the other hand, for a dosage of $4 \%$, we observe a slight increase in stress by simple compression of around 58\% for CSEBs compared to the ASEBs. For a dosage of $0 \%$, we observe a slight increase in stress by simple compression of around $57 \%$ for CEBs compared to the AEBs.

In terms of absorption rate, CSEBs resist up to one day before depigmentation is observed, whereas ASEBs, from the second hour of immersion, depigmentation is already visible. Thus, we can conclude that CSEBs have a low rate of swelling (porosity), hence a better resistance to humidity, which makes it on one hand more resistant to mechanical appeals (Three-point bending compression, simple compression) than CEBs and less absorbing on the other than AEBs. These findings firstly show that CSEBs are more resistant than ASEBs considering the maximum stress obtained by each specimen, in the same proportion of stabilized $(0 \%, 4 \%$ and 8\%) as well as simple compression and three point-bending compressions. With the intent to obtain the best characteristics of CSEBs and ASEBs from the three types of soil, we recommend a dosage of about $8 \%$ of cement.

\section{Acknowledgments}

We are also grateful to the general manager of MIPROMALO Yaounde where the experiments have been performed. One of us is grateful to Mr J. Deutou and Mr Loweh for their help during experiments.

\section{References}

AFNOR (1993a), NF P 94-051. Sols: reconnaissance et essai - Détermination des limites d'Atterberg Limite de liquidité à la coupelle-Limite de plasticité au rouleau.

AFNOR (1995a), NF P 94-056. Reconnaissance et essais - Identification granulométrique - Méthode de tamisage par voie humide.

AFNOR (1992), NF P94-057. Analyse granulométrique des sols, Méthode par sédimentation.

AFNOR (1993b), NF P 94-068. Mesure de la quantité et de l'activité de la fraction argileuse essai à la tâche. 
AFNOR (1995b), NF EN 197-1 (P15-101-1): Ciment-partie 1 : composition, spécifications et critères de conformité de ciment courants.

Akpokodje EG. (1985). The stabilization of some arid zone soils with cement and lime. Quarterly Journal of Engineering Geology London, 18, 173-180.

Amougou, J. A., Abossolo, S. A., Hindjang, M., (2015). Variabilité des précipitations à Koundja et à Ngaoundere en rapport avec les anomalies de la température de l'océan atlantique et el nino. Rev. Ivoire Sciences Technologie, $25: 111$ - 112.

Bahar, R., Benazzoug, M., Kenai, S., (2004). Performance of compacted cement - stabilised soil. Cem. Concr. Compos., $26: 811-820$.

Césaire, H., Adamah, M., Abdou, L., Georey, M., V., (2020). Impact of the Design of Walls Made of Compressed Earth Blocks on the Thermal Comfort of Housing in Hot Climate. Buildings, 10: 157.

Chrétien, M., Fabre, R., (2007). Recherche des paramètres d'identification géotechnique optimaux pour une classification des sols sensibles au retrait-gonflement. Géotechnique,: 91-106.

Dao, K., Ouedraogo, M., Millogo, Y., Aubert, J. E., Gomina, M., (2018). Thermal, hydric and mechanical behaviours of adobes stabilized with cement. Constr. Build. Mater., 158: 84 - 96.

Elisabete, R. T., Gilberto, M., Adilson, P. J., Christiane, G., (2020). Mechanical and Thermal Performance Characterisation of Compressed Earth Blocks. Energies, 13: 2978.

Ghorab H. Y., Anter A., El Miniawy H., (2007). Building with local materials: stabilized soil and industrial wastes. Materials and Manufacturing Processes., 22 : 157-162.

Guanqi L., Sisi C., Yihong W., and Ying C., (2021). Methods to Test the Compressive Strength of Earth Blocks. Hindawi Advances in Materials Science and Engineering, ID 1767238: 11 https://doi.org/10.1155/2021/1767238.

Houben, H., Rigassi, V., Garnier, P., (1996). Blocs de terre comprimée: équipements de production. CRATerre Bruxelles Belgique, ISBN: 2-906901-12-1.

Inim, I. J., Affiah, U. E., Eminue, O. O., (2018). Assessment of bamboo leaf ash/lime-stabilized lateritic soils as construction materials. Innovation Infrastructure Solution, 3: 32.

Kariyawasam, KKGKD., Jayasinghe, K., (2016). Cement stabilized rammed earth as a sustainable construction material. Constr. Build. Mater., 105: 519 - 527.

Ronglin, C., (2020). Mechanical and Thermal Behaviors of Cement Stabilized Compressed Earth Bricks. Earth Environ. Sci. 474 072090. doi:10.1088/1755-1315/474/7/072090.

Ruiz, G., Zhang, X., Edris, W. F., Cañas, I., Garijo, L., (2018). A comprehensive study of mechanical properties of compressed earth blocks. Constr. Build. Mater., 176: 566-572.

Meukam, P., Jannot, Y., Noumowe, A., Kofane, T.C., (2004). Thermo-physical characteristics of economical building materials. Constr. Build. Mater., 18: 438 - 442.

Morel J. C., Abalé P., Di Benedetto (2003). Essai in situ sur blocs de terre comprimée. Revue Française de Génie Civil, 7:2, 221-237, DOI 10.1080/12795119.2003.9692490.

Ntamack, G., Degho, T., Beda, T., Charif D'Ouazzane, S., (2012). Determination of Mechanical Characteristics of Compressed and Stabilized Earth Blocks by Cement, by the Mixture Cement and Sawdust, and by the Lime through the Elasticity-Damaging Coupling Model. International Journal of Science and Technology, ISSN 2224-3577: 669 - 670.

Sekhar, D. C., Nayak, S., (2018). Utilization of granulated blast furnace slag and cement in the manufacture of compressed stabilized earth blocks. Constr. Build. Mater., 166: 531-536. 
Toure, P. M., Sambou, V., Faye, M., Thiam, A., Adj, M., Azilinon, M., (2017). Mechanical and hygrothermal properties of compressed stabilized earth bricks (CSEB). J Build Eng., 13: 266 - 271.

Tran, K., Satomi, T., Takahashi, H., (2018). Improvement of mechanical behavior of cemented soil reinforced with waste cornsilk fibers. Constr. Build. Mater., 178: 204 - 210.

Walker, P. J., (2004). Strength and erosion characteristics of earth blocks and earth block masonry. J Mater Civ Eng., 16(5): 497 - 506.

Zhang, L., Gustavsen, A., Jelle, B.P., Yang, L., Gao, T., Wang, Y., (2017). Thermal conductivity of cement stabilized earth blocks. Constr. Build. Mater. 151: 504 - 511. 